\title{
AFINAL, O QUE É GÊNERO TEXTUAL NA LINGUÍSTICA SISTÊMICO-FUNCIONAL?
}

\section{AFTER ALL, WHAT IS TEXTUAL GENRE IN SYSTEMIC FUNCTIONAL LINGUISTICS?}

\author{
Wagner Rodrigues Silva* \\ Elaine Espindola
}

RESUMO: Neste artigo, realizamos um estudo crítico-descritivo sobre as principais perspectivas teóricas de gênero textual, produzidas internacionalmente na Linguística Sistêmico-Funcional (LSF). Os resultados mostraram compartilhamento de princípios sistêmicofuncionais entre as perspectivas teóricas investigadas, apesar dos enfoques diferenciados do gênero textual. Tais perspectivas foram agrupadas em clássica e tipológica. O estudo caracterizou a LSF como uma abordagem teórica aberta a constantes inovações, o que parece ser promissor para os estudos transdisciplinares da Linguística Aplicada desenvolvidos no Brasil.

PALAVRAS-CHAVE: Sociossemiótica. Registro. Gramática. (Con) texto.

ABSTRACT: The present paper presents a comparative study of the main theoretical perspectives concerned with textual genre as disseminated internationally in the realm of Systemic Functional Linguistics. Results have shown that scholars do share a systemic-

\footnotetext{
* Universidade Federal do Tocantins (UFT), Araguaína, Tocantins, Brasil, Doutor em Linguística Aplicada pela Unicamp, Professor e Pesquisador na UFT, E-mail: wagnersilva@uft.edu.br.

** The Hong Kong Polytechnic University (PolyU), Hong Kong, Doutora em Letras pela UFSC, Professora e Pesquisadora na PolyU, E-mail: elaine.espindola@polyu.edu.hk.
} 
functional ground for their approaches, but at the same time, these same scholars tend to focus on different analytical parameters of textual genre, which we have named here: classical and typological. We have also found that Systemic Functional Linguistics is a theory open for constant innovation; such finding seems to be quite propitious when set in the interface of the transdisciplinary studies of Applied Linguistics.

KEYWORDS: Socio-semiotics. Register. Grammar. (Con)text. 


\section{AFINAL, O QUE É GÊNERO TEXTUAL \\ NA LINGUÍSTICA SISTÊMICO-FUNCIONAL}

\section{INTRODUÇÃO}

No contexto brasileiro da Linguística Aplicada (LA), a pergunta que intitula este artigo, Afinal, o que é gênero textual na linguística sistêmico-funcional?, pode remeter nossos leitores aos debates instaurados na década de 90 sobre a configuração assumida pela LA no Brasil ${ }^{1}$. No âmbito desse debate, destacamos o trabalho intitulado "Afinal, o que é Linguística Aplicada?" (CELANI, 1992), ao qual, propositadamente, fazemos remissão neste artigo. Por um lado, a forma adverbial Afinal, seguida pela forma pronominal interrogativa $o$ que, na posição temática das perguntas-título mencionadas, apontam para um trabalho em curso, provavelmente, em estágio bastante avançado ou amadurecido. Por outro lado, essas perguntas podem ser lidas como tentativas de imposição de uma resposta única às perguntas elabora-

1 Este artigo faz parte das atividades de pós-doutorado desenvolvidas pelos autores deste artigo, na The Hong Kong Polytechnic University (PolyU), no Departamento de Língua Inglesa, sob a supervisão do Prof. Dr. Christian Matthiessen. As atividades de pós-doutorado do primeiro autor foram realizadas com bolsa da CAPES/Brasil - Proc. nº BEX 11536/128. A pesquisa desenvolvida pela segunda autora está cadastrada na PolyU, sob o número 4ZZ8W. O artigo contribui ainda para as atividades do grupo de pesquisa Práticas de Linguagens em Estágios Supervisionados - PLES (UFT/CNPq). 
das. Situando-nos no contexto científico brasileiro, optamos pela primeira leitura: pretendemos contribuir teoricamente com os estudos linguísticos brasileiros de gêneros textuais sem enveredar por disputas teóricas.

Neste artigo, realizamos uma revisão crítico-descritiva da noção teórica de gênero textual desenvolvida internacionalmente na Linguística Sistêmico-Funcional (LSF), demonstrando evidências da renovação teórica num processo ininterrupto de criação nos estudos linguísticos. A partir da nossa leitura, confrontamos duas perspectivas de abordagem dos gêneros textuais, aqui denominadas de clássica e tipológica. Atribuímos tal denominação à primeira por ser mais comumente compartilhada entre os estudiosos brasileiros da LSF e por se aproximar mais de outras abordagens teóricas sobre o assunto, as quais informam alguns estudos linguísticos no país (cf. MOTTA-ROTH, 2010; MOTTA-ROTH; HEBERLE, 2005; SILVA, 2012c; VIAN JR, 1997; VIAN JR; IKEDA, 2009; VIAN JR; LIMA-LOPES, 2005). Ou seja, tal denominação é motivada pela tradição dos estudos linguísticos sobre gêneros textuais, diferentemente de sentidos atrelados a erudição ou literatura antiga, os quais possam remeter a escolha lexical realizada. A denominação da segunda perspectiva é justificada pelo lugar periférico atribuído à noção propriamente dita de gênero, em função da relevância posta nos processos sociais que significam as atividades sociais do cotidiano (cf. ARAÚJO, 2007; GYSEL, 2013). Eliminamos possíveis juízos de valor entre tais perspectivas, acreditamos que elas sejam complementares. Apenas, salientamos que a abordagem tipológica pode trazer enfoques diferenciados para os estudos linguísticos aplicados brasileiros de gêneros textuais, além de pontuar percursos metodológicos alternativos a partir de gêneros para os estudos gramaticais ou as descrições linguísticas.

A metodologia de pesquisa aqui assumida corresponde à revisão crítica de referenciais teóricos bastante conhecidos na LSF, justificando a seleção realizada pela relevância dos estudos para a teoria focalizada. Eles foram situados nas perspectivas teóricas por nós identificadas como clássica (EGGINS, 2004; EGGINS; MARTIN, 1997; HASAN, 1996, 1989; MARTIN, 2012, 2001, 1997, 1992) e tipológica (HALLIDAY; MATTHIESSEN, 2013, 2004; MATTHIESSEN, 2013, 2012, 2009, 1993). A revisão teórica se configura pela comparação das duas perspectivas focalizadas, destacando as- 
pectos convergentes e divergentes entre os estudos revisados. Outros trabalhos sistêmico-funcionais desenvolvidos dentro e fora do contexto brasileiro são trazidos para a investigação, quando também são pontuadas tendências investigativas relevantes para o desenvolvimento científico nacional da LA.

Este artigo está organizado em três partes principais, além da Introdução, das Considerações finais e das Referências bibliográficas. Na primeira seção, Percursos paralelos - LSF/LA, discutimos aspectos da trajetória de desenvolvimento da LSF, articulando tal discussão a avanços nos estudos de gêneros textuais instaurados no contexto brasileiro da LA. Na segunda seção, Perspectiva clássica dos gêneros textuais, apresentamos aspectos convergentes e divergentes nos estudos dos gêneros textuais identificados como clássicos. Também pontuamos a flexibilidade teórica da LSF para propósitos investigativos diferenciados. Na terceira seção, Perspectiva tipológica dos gêneros textuais, descrevemos a perspectiva teórica em que a concepção de gênero se mistura às variáveis de registro da língua, em função da descrição do sistema linguístico, resultando numa diluição das fronteiras analíticas aparentemente delimitadas.

\section{PERCURSOS PARALELOS - LSF/LA}

Na década de 90, Celani (1992) destaca o amadurecimento da LA brasileira após a criação dos primeiros programas de pós-graduação sob o rótulo de Linguística Aplicada e da Associação Brasileira de Linguística Aplicada (ALAB). Consolidando-se enquanto campo de estudo interdisciplinar da linguagem e, posteriormente, transdisciplinar, a LA vem se fortalecendo como um campo autônomo de investigação científica, informado por diversas disciplinas igualmente alinhadas (Antropologia, Educação, Linguística, Psicologia, Sociologia), dentre as quais se encontra a Linguística. Ou seja, conforme afirma Celani (1992), as pesquisas desenvolvidas na LA "não são mera aplicação da Linguística” (p. 21). "As atividades inerentes às duas áreas não se colocam em uma relação de polaridade. Deveriam circular livremente naquela ponte com tráfego nos dois sentidos" (p. 22). Transcorridas mais de duas décadas dessa publicação, o tráfego entre as disciplinas parece fluir 
de maneira mais harmoniosa, apesar dos murmúrios pontuais que insistem em serem ouvidos nas encruzilhadas acadêmicas. Definitivamente, as contribuições parecem fluir em mão dupla, em algumas situações, tornando-se difícil o discernimento das fronteiras disciplinares.

Nos primórdios da LSF, o enfoque de problemas sociais envolvendo a linguagem, em diferentes instituições ou domínios sociais, não era concebido de forma diferenciada, quando comparado aos olhares críticos sobre a LA². Matthiessen e Halliday (2009: 16) afirmam que,

“na década de 1960, a LSF era 'impura’ porque foi concebida para ser aplicável. Recentemente, o potencial para aplicar a LSF tornou-se uma enorme vantagem, e pesquisas desenvolvidas para abordar problemas na comunidade, atualmente, estão sendo valorizadas, até mesmo na Linguística. Esse fenômeno é bastante encorajador - especialmente porque Halliday e outros pretendiam criar um tipo de linguística que pudesse ser utilizada em função da melhoria da condição humana." ${ }^{3}$

Mesmo não sendo o ensino de língua a única área de atuação dos linguistas aplicados, o desenvolvimento alcançado pela LA pode ser evidenciado pelas contribuições da disciplina para a elaboração das atuais diretrizes curriculares brasileiras para o ensino de línguas, vigentes há mais de uma década no cenário nacional: Parâmetros Curriculares Nacionais - PCN (BRASIL,

2 No contexto acadêmico asiático de produção deste artigo, a denominação Appliable Linguistics é utilizada para identificar o campo de atuação dos sistemicistas. Foi motivada para marcar o compromisso dos pesquisadores em resolver problemas humanos reais, envolvendo a linguagem, assim como inúmeras pesquisas brasileiras desenvolvidas na LA. Tal denominação não corresponde ao que compreendemos no Brasil por aplicação de Linguística. Matthiessen (2012) caracteriza essa Appliable Linguistics como uma síntese do que é realizado no que o autor compreende por Linguística e Linguística Aplicada.

3 'In the 1960s, LSF was 'impure' because it was designed to be appliable. The potential to apply LSF has now become a huge advantage, and research undertaken to address problems in the community is now being valued, also within linguistics. This is very encouraging - especially since what Halliday and others set out to do was to create a kind of linguistics that could serve as a resource to be used in improving the human condition". (MATTHIESSSEN; HALLIDAY, 2009: 16) 
1997, 1998a, 1998b, 2000) e Orientações Curriculares para o Ensino Médio - OCEM (2006). Após a publicação desses documentos, outros avanços continuaram se sucedendo no ensino brasileiro de línguas, envolvendo transformações nas metodologias de ensino, na produção de materiais didáticos e na formação de professores (cf. DORNELLES, 2012; GONÇALVES; FERRAZ, 2012; MELO; ANDRADE e SILVA, 2012; SILVA, 2012a; TENUTA; OLIVEIRA, 2011). No bojo dessas transformações, os estudos linguísticos aplicados dos gêneros textuais se fortaleceram significativamente no cenário nacional, uma vez que os gêneros são propostos como objetos de ensino nas referidas diretrizes. O texto é proposto como unidade de análise linguística, contrapondo-se à abordagem prescritivista da tradição do ensino de língua (cf. APARÍCIO, 2010; SILVA, 2011, 2009a, 2009b). As produções científicas sobre gêneros textuais também são intensificadas em função das inúmeras demandas emergentes para adequação das disciplinas escolares à proposta renovada de ensino.

As pesquisas linguísticas sobre gêneros são informadas por abordagens teóricas diversas no território brasileiro. As seguintes abordagens de origem estrangeira são destacadas por Borges (2012: 122): sócio-histórica/dialógica (Mikhail Bakhtin); sociorretórica/sócio-histórico cultural (Carolyn Miller, John Swales, Charles Bazerman, Amy Devitt); interacionista/sociodiscursiva de caráter psicológico - vigotskiano - e atenção didática voltada para língua materna (Bernard Schneuwly, Joaquim Dolz e Jean-Paul Bronckart); comunicativa (Hugo Steger, Elisabeth Gülich, Jörg Bergmann, Carol Berkenkotter); sociorretórica de caráter etnográfico voltada ao ensino de segunda língua (John Swales, Vijay Bhatia); sistêmico-funcional (Michael Halliday); análise crítica (Norman Fairclough, Gunther Kress) ${ }^{4}$.

A partir do diálogo entre diversas teorias, os estudos linguísticos brasileiros ganham características próprias. A título de exemplo, mencionamos a abordagem textual proposta por Marcuschi (2008) e (RIBEIRO; ROCHA;

4 Apesar de Borges (2012) apenas mencionar Michael A. K. Halliday como representante da abordagem sistêmico-funcional dos gêneros, destacamos que o autor parece não ser muito entusiasta em relação à noção teórica de gêneros textuais, diferentemente dos autores que situamos na perspectiva clássica. Para maiores detalhes, ver entrevista com o autor em Thompson e Collins (2001). 
COSCARELLI, 2010), também fortemente influenciada pela proposta francesa de sequências textuais de Jean-Michel Adam. Essa proposta textual foi desconsiderada por Borges (2012). Outro exemplo é a pesquisa desenvolvida por Motta-Roth (2010). A autora combina as concepções sociorretórica, sistêmico-funcional e sócio-histórica bakhtiniana dos gêneros textuais, em função da investigação de processos discursivos responsáveis pela midiatização de pesquisas científicas em publicações de popularização da ciência divulgadas na internet.

Ainda fazendo referência à pesquisa de Borges (2012), além da abordagem dialógica/sócio-histórica bakhtiniana, referência comum entre as diferentes correntes teóricas mencionadas, as perspectivas interacionista/sociodiscursiva e a sociorretórica são apresentadas como abordagens de mais aceitabilidade na educação brasileira. Os critérios utilizados pela autora para a escolha dessas abordagens foram: influência teórica sobre as diretrizes curriculares nacionais e abordagens teóricas informadas nas propostas de comunicação do maior evento científico brasileiro sobre gêneros textuais: Simpósio Internacional de Estudo de Gêneros Textuais - SIGET ${ }^{5}$. As abordagens que influenciaram diretamente a elaboração das diretrizes curriculares nacionais foram a dialógica/sócio histórica bakhtiniana e a interacionista/sociodiscursiva. A remissão feita por Borges (2012) à sociorretórica justifica-se pelas propostas de comunicação do referido evento.

Desconhecemos alguma influência direta exercida pela LSF na elaboração das diretrizes curriculares brasileiras ${ }^{6}$. Está entre as abordagens teóricas de menor ocorrência nas formas de comunicação apresentadas no evento científico mencionado. O que justificaria essa tímida interferência teórica e prática no cenário brasileiro? Algumas razões políticas, pelas quais não enveredaremos aqui, compreendendo inclusive facilidades de estabelecimento de convênios

5 Esse evento de porte internacional possui edições bianuais. A edição focalizada pela autora foi a 5a, ocorreu em agosto de 2009, na cidade de Caxias do Sul (RS), Região Sul. Atualmente, este evento encontra-se em sua 7 ${ }^{\text {a }}$ Edição, setembro de 2013, na cidade de Fortaleza (CE), Região Nordeste.

6 Considerando as contribuições teóricas originárias da Linguística Textual na elaboração dessas diretrizes (BRASIL, 2006, 2000, 1998a, 1998b, 1997), a qual sofreu significativas influências da LSF, podemos afirmar que, indiretamente, houve contribuições da LSF na elaboração das referidas diretrizes curriculares brasileiras. 
entre universidades europeias e brasileiras, contribuiriam com justificativas para o cenário delineado. A inexpressiva interferência mencionada não reduz o mérito das pesquisas brasileiras informadas pela LSF, apresentando importantes encaminhamentos teóricos ou práticos (cf. BARBARA; MOYANO, 2011; MOTTA-ROTH, 2010; NININ; BARBARA, 2013; SILVA, 2012c; SILVA; PEREIRA, 2013; VIAN JR., SOUZA; ALMEIDA, 2011). A LSF informa significativamente pesquisas linguísticas e políticas de ensino de língua além das fronteiras brasileiras, a exemplo dos programas de letramento baseados em gênero no contexto escolar australiano (cf. CHRISTIE; DEREWIANKA, 2008; EGGINS; MARTIN, 1997; HASAN; MATTHIESSEN; WEBSTER, 2007; MARTIN; ROSE, 2008; MATTHIESSEN, 2009).

Tomando o texto como principal objeto de investigação e concebendo-o enquanto produto sociossemiótico orientador e revelador das atividades interacionais cotidianas, a LSF possibilita a construção de objetos de investigação a partir do diálogo entre saberes teóricos originários de diferentes disciplinas ou campos do conhecimento, mantendo o sistema linguístico no centro da análise realizada ${ }^{7}$. O texto é produto no sentido de podermos nos debruçar sobre a sua materialidade para estudo, podendo ser representado por sistemas linguísticos. O texto também é processo, pois representa eventos interativos onde ocorrem trocas ou construções de sentidos entre os participantes da interação, numa rede de significados potenciais (HALLIDAY, 1989: 10). Esse caráter processual do texto remete-nos diretamente às concepções de gênero discutidas na próxima seção deste artigo.

A LSF vem se expandindo internacionalmente de forma expressiva e constante, sendo Michael A. K. Halliday o principal idealizador da teoria (cf. HALLIDAY, 1994, 1978, 1973). Configura-se como uma teoria de reflexão e de ação sobre diferentes manifestações da linguagem em contextos de uso. Novas contribuições são adicionadas ao sistema descritivo da LSF, conforme necessidade dos sistemas linguísticos observados, justificando a

Uma definição de texto apresentada por Hasan (1996: 51) aponta diretamente para uma das concepções de gênero discutida neste artigo. Segundo a autora, "texto é uma expressão verbal da atividade social. Por ser produto da atividade social, uma estrutura textual generalizada pode ser encontrada". / "The text is, here, a verbal expression of social activity, and so by reference to the social activity, a generalized statement of text structure can be achieved". 
caracterização teórica como sistema aberto e dinâmico, de maneira que permita refletir as línguas focalizadas, além de outros sistemas sociossemióticos investigados (cf. MATTHIESSEN, 2009). Na década de 1980, por exemplo, o nível contextual, representado nos estratos de organização da linguagem (Figura 2), foi desdobrado nos estratos de registro, gênero e ideologia, a partir dos trabalhos desenvolvidos por J. R. Martin e outros membros da equipe (cf. MATTHIESSEN; HALLIDAY, 2009; THOMPSON; COLLINS, 2001).

De acordo com Matthiessen e Halliday (2009: 11), o ambiente acadêmico mudou de forma bastante significativa desde o princípio dos estudos da LSF, na década de 1960. Na LSF, essas mudanças desencadearam esforços investigativos com e através de outras disciplinas do conhecimento. Tal abordagem responde a demandas de pesquisa realizada na LA. Além de conceber a linguagem como objeto de investigação inter/transdisciplinar, as pesquisas na LA focalizam o desvendamento e a superação de relações assimétricas entre atores sociais em diversas interações do cotidiano. A articulação entre LSF e LA, mediada por diálogos com outras disciplinas ou campos do conhecimento, parece um percurso promissor para o desenvolvimento ou a produção da inovação na LSF.

Nos primeiros delineamentos teóricos propostos por Michael A. K. Halliday (cf. MATTHIESSEN, 2009), são mencionados alguns usos da LSF em diferentes esferas sociais e com diferentes propósitos, tais como: planejamento de currículo educacional; descrição e comparação de diferentes sistemas semióticos, compreendendo diferentes línguas ou modos de realização; análise de redes de comunicação no local de trabalho; e implementação de modelos linguísticos para sistemas computacionais. Esses usos também são ilustrativos de algumas áreas de atuação dos linguistas aplicados que utilizam a sistêmico-funcional como referência nas pesquisas realizadas.

Pressões internas e externas incidem sobre a teoria, provocando mudanças no intuito de expandir o domínio de operação da LSF. Para Matthiessen (2009: 14), a abrangência teórica tem se estendido da mesma forma que cartógrafos estendem a cobertura de mapas através do mundo: primeiro se esboça o escopo da área, depois, gradualmente, são preenchidos os espaços 'vazios' para só então mudar a escala do mapa. Essas mudanças são possíveis pela natureza relacional e dimensional entre contextos e sistemas linguísti- 
cos, delineada na teoria focalizada. A LSF sempre esteve e continua receptiva a inovações, ou seja, às contribuições teóricas que possam desencadear o aumento do alcance e da precisão das análises linguísticas propostas.

O mapeamento das transformações sofridas pela LSF e das motivações para as mudanças observadas na história da teoria contribui para visualizarmos o desenvolvimento epistemológico em construção (cf. DELU et al., 2007; MATTHIESSEN, 2009, 2007). Especificamente para o contexto brasileiro, tal mapeamento seria bastante elucidativo, tanto para a LSF quanto para a própria LA. As áreas de pesquisa em LSF e, consequentemente, os encaminhamentos teóricos para situações pedagógicas, apreendem diferentes dimensões de organização da linguagem. Na Figura 1, releitura de Matthiessen (2009: 25), representamos duas dimensões orientadoras da análise linguística a partir de uma perspectiva léxico-gramatical. São parâmetros para a descrição de registros, podendo se desdobrar na descrição de gêneros textuais, a partir da combinação de ângulos de entrada para a investigação sistêmico-funcional.

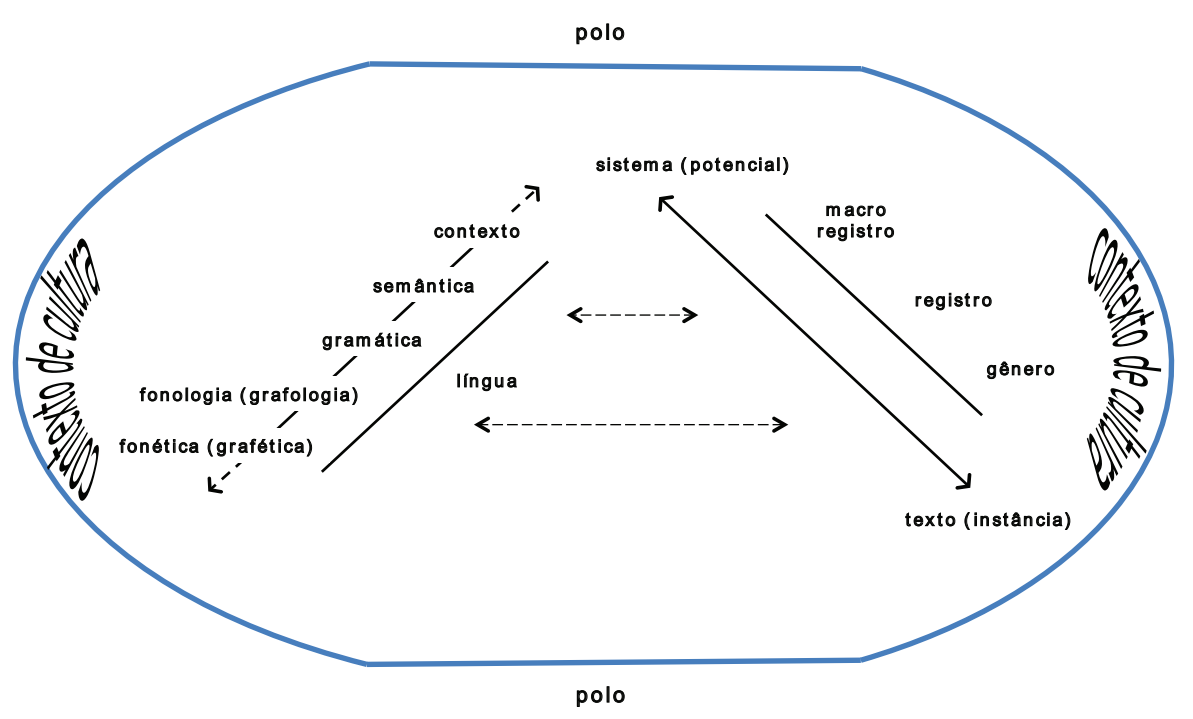

(i) hierarquia da estratificação

(II) escala da Instanclaçăo

Figura 1: perspectiva global da linguagem 
A hierarquia da estratificação (i) é representada na linha que vai do contexto até a fonética ou grafética. A escala de instanciação (ii) é representada na linha que vai do sistema até a instância. A visualização das duas dimensões permite-nos localizar a gramática na hierarquia de estratificação do funcionamento da linguagem. É possível relacionar aspectos léxicogramaticais aos estratos semântico, fonológico ou grafológico da língua. Ao visualizarmos o estrato léxico-gramatical na escala de instanciação, torna-se possível relacionar padrões linguísticos, encontrados em textos escritos e falados, ao sistema potencial da língua. $\mathrm{O}$ enfoque investigativo sobre aspectos da língua, estudados em áreas específicas dos estudos linguísticos, pode ser complexificado se explorarmos tais dimensões globais da organização da língua em contexto.

A escala de instanciação é definida como um princípio de organização sistêmica, no qual são operados sistemas diversos: linguísticos, físicos, biológicos, sociais e semióticos. De acordo com Matthiessen e Halliday (2009: 13):

A língua é uma propriedade de coletivos sociais constituídos por pessoas que desempenham diferentes papéis institucionais em diferentes redes sociais. Porque a língua é social, ela é, então, um sistema socialmente distribuído, sempre mantido e mudado nas interações entre pessoas com papéis diferentes. A língua também é um sistema biológico: ela é inerente aos organismos biológicos e está sujeita a fatores fenotípicos e genotípicos. É o único sistema humano que nos integra mais especificamente, que integra diferentes regiões e processos de nossos cérebros utilizando outras partes do corpo para produção e percepção da mesma. Finalmente, a língua é também um sistema físico: ela é manifestada fisicamente por ondas sonoras, marcas em tabuletas de argila ou em papel, movimentos em espaço de sinalização, e assim por diante. ${ }^{8}$

8 "Language is a property of social collectives made up by persons taking up different institutional roles in different social network. Being social, language is thus a socially distrib- 
A escala representa instâncias ou realizações observáveis do potencial implícito no sistema da língua. A escala é importante para delimitar o escopo teórico-metodológico das investigações científicas desenvolvidas na LA. A partir do polo de instância, os estudos sistêmico-funcionais são conduzidos por meio da observação, amostragem e análise textual, caminhando na direção do polo do sistema potencial. Ao focalizarmos a análise linguística entre o polo da instância e o meio da escala, identificamos aspectos instanciais característicos de gêneros específicos, envolvendo, portanto, registros determinados. Ao deslocarmos a análise na direção do polo oposto, no sistema potencial, as diferenças de registro desaparecem gradualmente, permitindo ao analista fazer generalizações a respeito do sistema potencial da língua (MATTHIESSEN; HALLIDAY, 2009: 82). Essa perspectiva global de funcionamento da linguagem é retomada ao nos determos à abordagem tipológica de gêneros, na seção Perspectiva tipológica dos gêneros textuais.

$\mathrm{Na}$ (i) hierarquia da estratificação, de acordo com Matthiessen (2009), a atenção dada ao discurso falado, por exemplo, tende a focar no nível de conteúdo e contexto, deixando os sistemas fonológicos e prosódicos de lado e, até mesmo, os cinésicos como elementos paralinguísticos. A partir da publicação de Halliday e Greaves (2008), esse cenário vem mudando. Estudos concentram esforços na investigação da prosódia semântica na análise de discurso falado, concebida como um ramo da Análise do Discurso informada pela LSF, complementando, portanto, os estudos focados em contexto (cf. BOWCHER; SMITH, 2013). Na (ii) escala de instanciação, o enfoque da pesquisa recai sobre a instância ou sobre o sistema potencial ou, até mesmo, sobre uma combinação dos dois. São exemplos: os Estudos da Tradução, os quais, normalmente, localizam-se no polo da instância; os Estudos Tipológicos e Comparativos, geralmente, localizam-se no polo do sistema potencial (MATTHIESSEN, 2009).

uted system, always being maintained and changed in interactions among people in different roles. Language is also a biological system: it is embodied in biological organisms and is subject to both phenotypic and genotypic factors. It is the one human systems that integrates us - more specifically, that integrates different regions and processes of our brains, using other parts of the body for production and perception. Finally, language is also a physical system: it is manifested physically as sound waves, marks on clay tablets or paper, movements in a signing space, and so on" (MATTHIESSEN; HALLIDAY, 2009: 13). 
A (i) hierarquia da estratificação dita a especialidade do estudo linguístico, ao passo que a (ii) escala de instanciação dita o nicho de pesquisa focalizado. $\mathrm{Na}$ abordagem clássica dos gêneros textuais, focalizada na próxima seção, o contexto é teorizado e modelado em termos de estratificação - contexto de situação e contexto de cultura (Figura 2). Na abordagem tipológica dos gêneros, o contexto é teorizado e modelado em termos da matriz que surge a partir da combinação da (i) hierarquia de estratificação com a (ii) escala de instanciação, tendo como ponto de entrada para análise o nível semântico de realização textual (Figura 1).

\section{PERSPECTIVA CLÁSSICA DOS GÊNEROS TEXTUAIS}

Nesta seção, tomamos como principais referenciais teóricos pesquisas produzidas por Ruqaiya Hasan, James Robert Martin e Suzanne Eggins, as quais, ao dialogarem, convergem para a abordagem teórica aqui denominada de clássica, pois os gêneros textuais são focalizados diretamente. Conforme mencionado por Eggins (2004: 84), a teoria dos gêneros permite-nos trazer para a consciência conhecimentos culturais compartilhados a partir da descrição de inúmeras formas linguísticas utilizadas para interagir socialmente, além de nos permitir refletir criticamente sobre como a cultura nos envolve. A noção de gênero fortalece o papel desempenhado pelo contexto na LSF9. Nos termos de Eggins e Martin (1997: 232), "cada texto parece trazer com ele algumas influências do contexto em que foi produzido. O contexto entra no texto pela influência das palavras e estruturas utilizadas pelos seus produtores"10.

Apresentamos a Figura 2, adaptada a partir de Martin (1997: 8), como representação da organização da linguagem sob os parâmetros da LSF. Há três

\footnotetext{
9 A principal hipótese defendida por Hasan (1989: 52) era que "texto e contexto estão tão intimamente relacionados que não é possível conceituar um sem fazer referência ao outro" / "text and context are so intimately related that neither concept can be enunciated without the other".

10 "each text appears to carry with it some influences from the context in which it was produced. Context, we could say, gets 'into' text by influencing the words and structures that text-producers use". (EGGINS; MARTIN, 1997: 232).
} 
estratos interconectados, destacando a mútua interferência entre a gramática do sistema linguístico, responsável por três metafunções da linguagem; o contexto de situação, realizado por três variáveis de registro; e o contexto de cultura, onde se localiza o gênero. Os estratos desencadeiam enfoques analíticos diferentes a partir das categorias propostas de análise linguística, as quais proporcionam maior abstração analítica na medida em que o enfoque recai sobre estratos mais externos da representação. Poderíamos, por exemplo, acrescentar outro círculo menor para representar a fonologia ou a grafologia, nível de estudo mais concreto da língua, e, até mesmo, um círculo maior para representar a ideologia, nível mais abstrato de enfoque da linguagem para Martin (2012: 150). Tal rigidez na delimitação das fronteiras entre estratos é justificada para fins didáticos. Nas efetivas práticas de linguagem, essas bordas desaparecem. Nesta seção, esclarecemos as terminologias mencionadas.

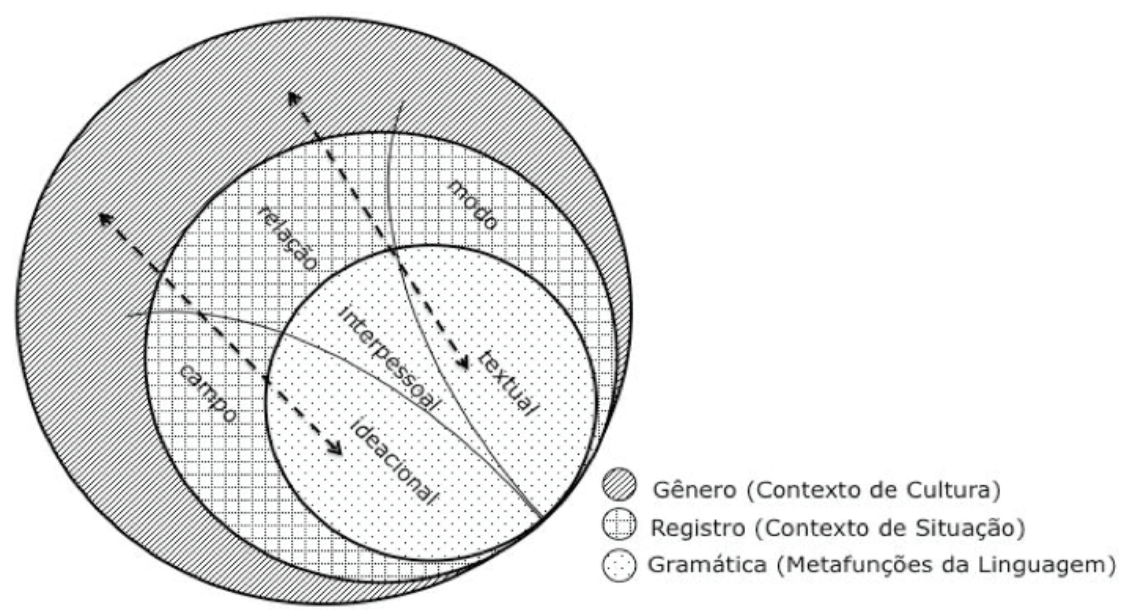

Figura 2: relação entre língua e contexto social em estratos

No estrato mais externo dos três representados na Figura 2, encontramos o contexto de cultura informando os textos, que, por sua vez, são produtos dos sistemas linguísticos postos em funcionamento em diferentes situações interativas. Apesar da significativa abstração envolvendo esse contexto, podemos afirmar que ele é responsável por construções sociais mais amplas, 
envolvendo, por exemplo, ideologias, práticas e saberes produzidos em culturas específicas. Compreenderia um nível mais pragmático em sentido amplo, nas análises linguísticas. Para Martin e Rose (2008: 17), a cultura envolve um grande conjunto de gêneros potencialmente caracterizáveis, os quais são reconhecíveis por seus membros. Os artigos, resenhas, relatórios, monografias e teses ilustram alguns gêneros textuais utilizados para propósitos diferenciados por membros integrantes da instituição universitária. Ainda nos termos dos autores, a cultura não seria, portanto, "uma selva imprevisível de situações sociais" (MARTIN; ROSE, 2008: 17) ${ }^{11}$.

No estrato intermediário, encontramos o contexto de situação, identificador da situação interativa imediatamente instaurada, a qual será sempre única. Esse contexto é focalizado pela análise da materialidade linguística por meio das três metafunções da linguagem. Essas estão situadas no estrato mais interno, na realização léxico-gramatical representada, e são realizadas por diferentes sistemas linguísticos. Comparadas ao contexto de cultura, as escolhas linguísticas são mais dinâmicas no contexto de situação, pois cada texto resulta em escolhas pontuais no sistema da língua, mesmo que tais escolhas sejam influenciadas pelo contexto de cultura. Nos termos de Gouveia (2008: 114), "um texto ocorre sempre em dois contextos, um dentro do outro: o contexto de situação e o contexto de cultura" (destaques do original).

$\mathrm{Na}$ interação instaurada no contexto de situação, podemos observar mais diretamente o conteúdo da ação social (campo), o envolvimento dos participantes (relação) e a forma de organização da língua (modo). Tais aspectos contextuais correspondem às variáveis de registro do texto. O registro é uma categoria de base semântico-discursiva que configura sentidos característicos de situações interativas pontuais. Os constituintes dos diferentes níveis de análise linguística (fonológico, lexical, gramatical) funcionam como índices para os sentidos construídos no contexto interativo imediato, envol-

${ }^{11}$ De forma bastante esclarecedora, Motta-Roth e Heberle (2005:15) afirmam que "um conjunto compartilhado de contextos de situação constitui um dado contexto de cultura, sistema de experiências com significados compartilhados. Assim, o sujeito é constituído pela soma de suas próprias interações e pelos códigos semióticos em funcionamento nas comunidades de que participa. (...) O contexto de cultura resulta, portanto, da padronização do discurso em termos dos atos retóricos ou atos de fala realizados por meio da linguagem em circunstâncias específicas, com características retóricas recorrentes". 
vendo as situações instauradas de produção e de recepção textual (HALLIDAY, 1989: 41).

Cada variável de registro está relacionada diretamente a uma das três metafunções da linguagem, denominadas de ideacional, interpessoal e textual, materializadas na superfície textual. Tratando-se de textos falados ou escritos, focalizamos a análise léxico-gramatical para descrever essas metafunções. As duas primeiras metafunções fazem referência a fenômenos sociais semiotizados nos usos linguísticos. Podemos observar o que ou quem participa da ação (sistema de TRANSITIVIDADE), e as relações entre atores sociais estabelecidas nas situações interativas (sistema de MODO), respectivamente. A terceira metafunção diz respeito à organização do próprio texto, à maneira de apresentação dos significados ideacionais e interpessoais como informação compartilhada pelos interactantes no contexto corrente (sistema de TEMA). A metafunção ideacional compreende duas formas de representação do mundo. A primeira - a metafunção experiencial - é responsável por modelar experiências do mundo exterior e interior do falante em termos de conteúdo. A segunda - a metafunção lógica - fornece os recursos para construir essas experiências como uma rede de fenômenos inter-relacionados. (cf. MATTHIESSEN; HALLIDAY, 2009: 53 e 54). Nos termos de Eggins (2004: 65):

tudo o que temos para avançar na análise de gênero é a linguagem - as palavras e estruturas utilizadas pelos usuários. Tecnicamente, podemos observar que é por meio da linguagem que os gêneros se realizam. É por meio dos padrões discursivo-semânticos, léxico-gramaticais e fonológicos do código linguístico que o nível contextual do gênero é realizado ou expresso pela linguagem. ${ }^{12}$

\footnotetext{
12 "all we have to go on in analysing genre is language - the words and structures speakers use. Technically, we can see that it is through language that genres get realized. It is through the discourse-semantic, lexico-grammatical and phonological patterns of the language code that the contextual level of genre is realized through, or expressed, in language" (EGGINS, 2004, 65).
} 
A relação dimensional dos dois estratos mais internos na Figura 2 está sintetizada no Quadro 1, elaborado a partir de Eggins (2004), Halliday (1994), Halliday e Matthiessen (2004):

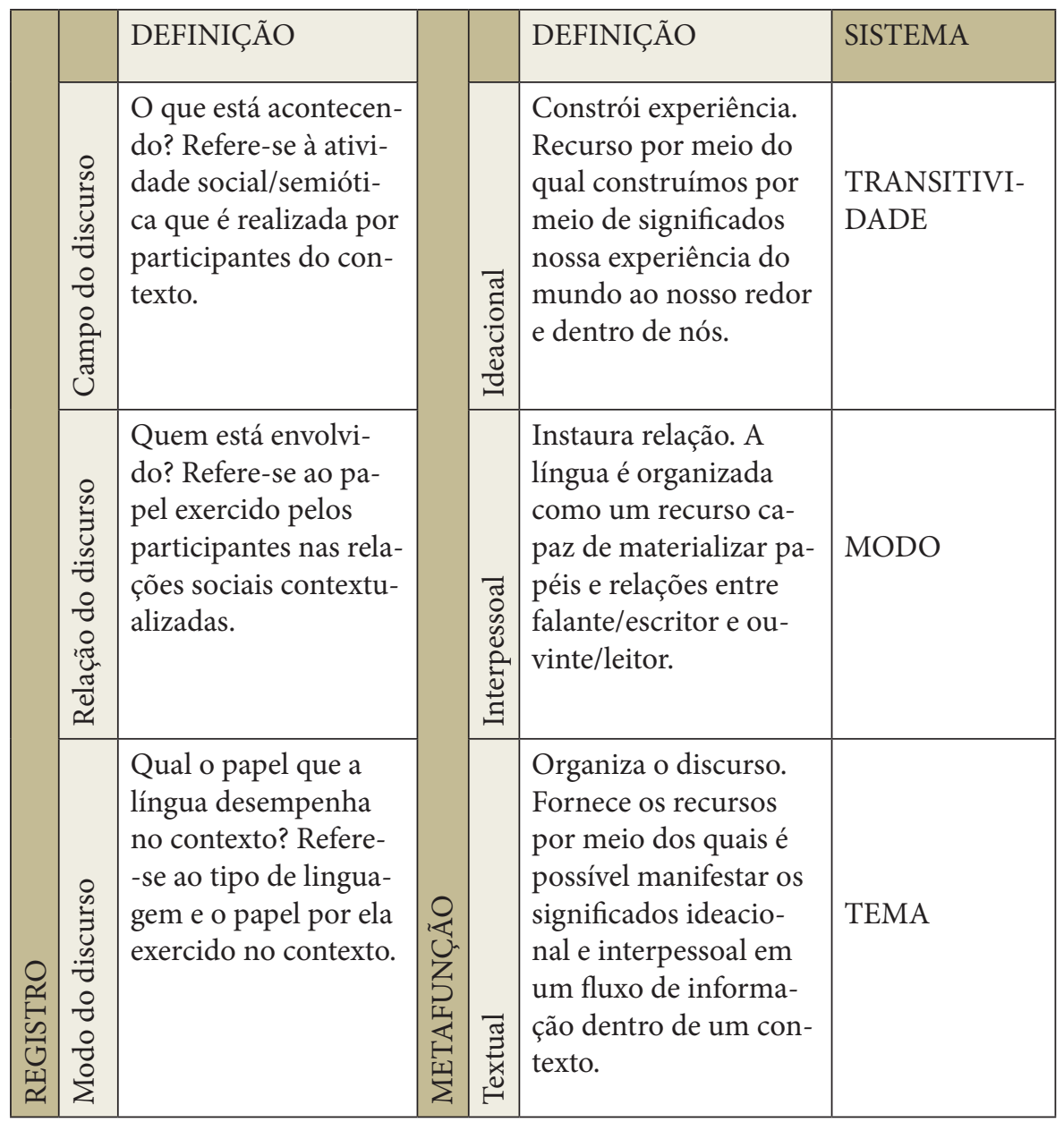

Quadro 1: síntese conceitual

Considerando a evidente ênfase dada aos aspectos formais na teoria, acreditamos que, tratando-se do estudo dos gêneros, precisamos ser cautelosos na mobilização das categorias analíticas propostas na LSF, afinal gêneros não são simplesmente formas ou estruturas. A esse respeito, são es- 
clarecedoras as considerações reproduzidas adiante realizadas por Gouveia (2008: 118). Isso nos revela a necessidade de explorarmos e conhecermos mais profundamente a abstração que ainda envolve o contexto de cultura.

a análise do processamento textual associado à expressão de gênero não é especificamente linguística, no sentido de que não decorre exclusivamente do conhecimento da gramática, mas do conhecimento do mundo e das manifestações de cultura simbólica que são relevantes numa dada comunidade.

Diferentemente de Eggins (2004) e Martin (1992) e (EGGINS; MARTIN, 1997), a categoria de contexto configuracional (CC) é proposta por Hasan (1989: 55) para reunir as variáveis de registro. Ou seja, temos uma categoria alternativa para o que foi denominado de contexto de situação. Podemos relacionar esse CC a três outras subcategorias propostas pela autora para analisar o contexto que circunscreve o gênero conto infantil: contexto de criação; contexto de audiência; e contexto reconstituído (HASAN, 1996: 62). Tais subcategorias parecem reunir três olhares sobre o gênero, os quais, numa perspectiva dialógica da linguagem (BAKHTIN, 1986), identificamos como olhar do enunciador; do enunciatário e do analista. Tal caracterização do CC está sintetizada na Figura 3.

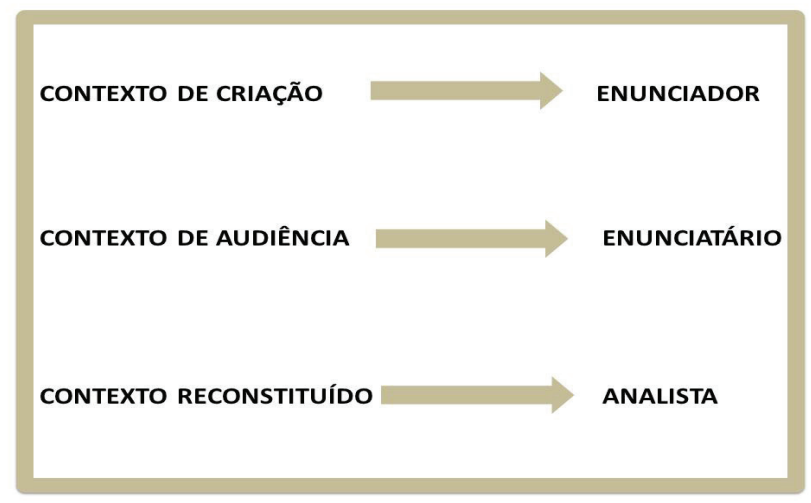

Figura 3: contexto de configuração 
O contexto de criação compreende influências no texto das convenções artísticas possuídas pela comunidade em que está inserido o produtor ou enunciador. As concepções da audiência e as preocupações pessoais possuídas pelo produtor também informam o contexto de criação. $O$ de audiência (ou de contato com a audiência) corresponde à situação de recepção do texto pela audiência ou enunciatário, envolvendo a construção de sentidos a partir de atitudes compartilhadas ou individuais. O reconstituído corresponde às estratégias linguísticas pelas quais os gêneros ganham estruturas textuais padronizadas. Tais subcategorias parecem dialogar com as metafunções da linguagem, ainda que não haja uma correspondência direta entre os agrupamentos de subcategorias. É sobre o último subcontexto que as lentes analíticas da autora parecem ser lançadas com mais intensidade ao apresentar uma abordagem própria de descrição de gêneros (HASAN, 1996: 63).

O princípio sistêmico da teoria, caracterizado por escolhas linguísticas realizadas especialmente no eixo paradigmático, continua sendo aplicado à noção de gênero textual. Eggins (2004: 66) esclarece que os gêneros são formas diferentes de uso da linguagem e que os usuários fazem diferentes escolhas léxico-gramaticais, conforme o propósito que desejam alcançar. Mas, finalmente, o que são gêneros textuais na abordagem clássica da LSF? Em Eggins (2004: 54), encontramos uma definição que retoma diretamente a noção de contexto de cultura a que fizemos referência previamente: "gênero como 'propósito cultural' de textos (...) textos expressam gêneros por meio de padrões estruturais e realizacionais". Partindo da característica sociossemiótica da teoria, a funcionalidade do gênero é destacada, bem como as formas padronizadas construídas socialmente em resposta à circulação dos textos numa dada cultura.

Duas perguntas são propostas pela autora para auxiliar a análise dos gêneros na perspectiva teórica aqui focalizada:

1. "Quais são os aspectos situacionais que precisam reocorrer para duas situações serem percebidas pelos interactantes como suficientemente similares para acionar um gênero corriqueiro?" 
2. "Quais são os aspectos de uso da língua que são percebidos como padrões 'relativamente consistentes' de significado em situações recorrentes?"13

Insistindo na padronização, a autora apresenta três aspectos a serem considerados na caracterização da identidade genérica, de maneira que possamos verificar as semelhanças entre textos pertencentes ao mesmo gênero: "a coocorrência de um agrupamento contextual particular ou configuração de registro"; "estágios do texto ou estrutura esquemática"; e "padrões de realização no texto" (EGGINS, 2004: 56). Nessa perspectiva, além de considerar os usos linguísticos padronizados, identificáveis pelas variáveis de registro e pelas metafunções da linguagem, a autora faz referência à estrutura esquemática do gênero (EEG), que são os estágios ou as etapas de organização do gênero, conforme conceituação amplamente propagada por James Robert Martin (Quadro 2). A categoria de EEG também é utilizada pelo autor para descrever gêneros textuais.

Apesar de insistirmos na noção de padrões de uso, envolvendo escolhas na microestrutura (metafunções e registro) ou macroestrutura linguística (estágios e elementos funcionais), lembramos que a relação entre texto e contexto é probabilística e não determinística (EGGINS; MARTIN, 1997: 236). Esse fato está relacionado à representação da (ii) escala de instanciação mencionada na seção anterior, ou seja, a probabilidade de realização textual se instaurar a partir das potencialidades do sistema linguístico de referência, o qual, por sua vez, segue a dinâmica natural das línguas. Nesse sentido, Vian Jr e Lima-Lopes (2005: 34) afirmam que "o gênero é encarado como um elemento mutável; sofre modificações advindas das interações nas quais ocorreu. Por conseguinte, cada ação social gerará gêneros que a tornam particular, em função das variáveis de registro". Sobre a instabilidade envolvendo registro e gênero, Gouveia (2008: 115) afirma que

\footnotetext{
13 "What aspects of situations need to recur for two situations to be felt by interactants to be 'similar enough' to call for the habitualized genre? In what aspects of our language use do we see the 'relatively consistent' patterns of meaning in recurrent situations?" (EGGINS, 2004: 58).
} 
enquanto as motivações de registro ajudam a tornar os textos diferentes entre si, as motivações de gênero ajudam a torná-lo semelhantes, em função de uma certa estabilidade nas práticas e convenções associadas à sua produção. (...) dois textos podem ser do mesmo gênero e serem, portanto, muito semelhantes a esse nível, mas mostrarem uma grande variação em termos de registro, sendo, portanto, também muito diferentes.

Cada EEG contribui para a produção de sentido global necessário para o uso do gênero. Numa análise descritiva, esses estágios podem ser identificados por critérios formais ou funcionais. Eggins (2004: 60) assume esses últimos critérios para análise de gênero, pois enquanto os formais apenas dizem algo sobre itens linguísticos utilizados no gênero, os critérios funcionais revelam como os usuários se apropriam de recursos linguísticos e alcançam o propósito global do texto. Acreditamos que a opção por esses últimos critérios não invalida contribuições advindas da mobilização dos critérios formais.

A organização dos gêneros em estágios ou etapas parece consensual na LSF, o que é confirmado pela recorrente reprodução da definição de gênero textual apresentada por James Robert Martin em diferentes produções das quais o autor participa (MARTIN; MATTHIESSEN, 2012: 4), (MARTIN, 2001: 288 e 317), (MARTIN, 1992: 505), (MARTIN; EGGINS, 1997: 243), (MARTIN; ROSE, 2008: 6) e (MARTIN; WHITE, 2005: 32). Há pequenas variações na definição reproduzida, porém o conteúdo básico é mantido. Isso também acontece em produções científicas em que James Robert Martin não participa da autoria nem a ele é realizada referência explícita, conforme observamos em Gouveia (2008: 116), no contexto investigativo europeu:

o gênero de um texto é, portanto, identificável como a sequência de etapas ou passos funcionais distintos por meio dos quais esse texto se desenvolve, sendo que as possíveis variações no domínio do gênero são o reflexo 
de diferentes encenações na sequencialização e estruturação dessas etapas.

(GOUVEIA, 2008: 116)

No contexto brasileiro, a abordagem dos gêneros proposta por James Robert Martin foi denominada de teleológica em Vian Jr. (1997) e em Vian Jr. e Lima-Lopes (2005) ${ }^{14}$. Apresentamos a definição de gênero no Quadro 2, quando também reproduzimos três desdobramentos do conteúdo textual nas palavras de Martin e Rose (2007: 8). Em diferentes apropriações dessa definição na LSF, a forma de concepção dos estágios ou etapas parece sofrer diferenciações sutis, as quais, para alguns leitores, podem ser imperceptíveis ou irrelevantes.

\begin{tabular}{|l|l|l|}
\hline GÊNERO & \multicolumn{2}{|l|}{$\begin{array}{l}\text { É um processo social organizado por estágios e orientado para } \\
\text { objetivos. }\end{array}$} \\
\hline SOCIAL & $\begin{array}{l}\text { ORGANIZADO } \\
\text { POR ESTÁGIOS }\end{array}$ & $\begin{array}{l}\text { ORIENTADO } \\
\text { PARA OBJETIVOS }\end{array}$ \\
\hline $\begin{array}{l}\text { Porque par- } \\
\text { ticipamos da } \\
\text { elaboração do } \\
\text { gênero coleti- } \\
\text { vamente. }\end{array}$ & $\begin{array}{l}\text { Porque normalmente o gêne- } \\
\text { ro demanda-nos etapas para } \\
\text { alcançarmos nossos objetivos. }\end{array}$ & $\begin{array}{l}\text { Porque utilizamos gênero para } \\
\text { pôr coisas em prática. }\end{array}$ \\
\hline
\end{tabular}

Quadro 2: definição de gênero para James Robert Martin ${ }^{15}$

A noção de EEG proposta por Eggins (2004) dialoga diretamente com as categorias de estrutura potencial (EP) ou estrutura potencial do gênero (EPG), criadas por Hasan $(1996,1989)$ para designar "uma categoria abstrata, descritiva de uma gama completa de estruturas disponíveis no limite de um

${ }^{14}$ No dicionário eletrônico Michaelis (http://michaelis.uol.com.br/), teleologia é definida como "teoria das causas finais; conjunto de especulações que têm em vista o conhecimento da finalidade, encarada de modo abstrato, pela consideração dos seres, quanto ao fim a que se destinam" (29/03/2013).

15 "A genre is a staged, goal-oriented social process. Social because we participate in genres with other people; goal-oriented because we use genres to get things done; staged because it usually takes us a few steps to reach our goals". (MARTIN; ROSE, 2007: 8) 
dado gênero"16. A EPG demonstra possibilidades de instanciação de estruturas textuais num gênero, ou seja, a estrutura textual de um gênero pode variar dentro das fronteiras delimitadas na EPG. Essa categoria é composta por três tipos de estágios, os quais, de acordo com a autora, são denominados de elementos obrigatórios, opcionais e iterativos (ou recursivos), conforme a funcionalidade por eles desempenhada na estrutura textual. A escolha desses elementos para compor a estrutura textual é análoga às escolhas realizadas no sistema da língua: sofrem influências contextuais.

Na perspectiva proposta por Hasan $(1996,1989)$, os obrigatórios são os identificadores do gênero, pois correspondem aos elementos sempre encontrados nos textos pertencentes ao mesmo gênero. A ocorrência desses elementos permite aos usuários o reconhecimento da completude do gênero. Nas palavras de Hasan (1989: 62), “os elementos obrigatórios definem o gênero a que o texto pertence; a ocorrência de todos esses elementos numa ordem específica corresponde a nossa percepção de completude ou incompletude do texto" ${ }^{17}$. Os opcionais correspondem aos elementos cuja presença ou ausência não é determinante para identificação do gênero. Garantem a instabilidade característica da linguagem. Os iterativos ocorrem mais de uma vez na estrutura textual, podendo agregar as funções de elementos obrigatórios e opcionais.

No Quadro 3, apresentamos uma síntese descritiva dessas variáveis caracterizadoras da EPG. O elemento adicional identificado como sequência é utilizado para informar a relevância da disposição dos elementos funcionais para a caracterização da EPG. No referido quadro, optamos por retextualizar em forma de pergunta a descrição apresentada por Hasan (1996: 56), dessa forma pretendemos instaurar aqui uma maior aproximação deste artigo com o leitor.

\footnotetext{
16 "The GSP is an abstract category; it is descriptive of the total range of textual structures available within a genre". (HASAN, 1996: 53)

17 "the obligatory elements define the genre to which a text belongs; and the appearance of all this elements in a specific order corresponds to our perception of whether the text is complete or incomplete". (HASAN, 1989: 62)
} 


\begin{tabular}{|l|l|}
\hline PERGUNTAS & ELEMENTOS \\
ORIENTADORAS & FUNCIONAIS \\
\hline 1. Quais elementos devem ocorrer? & Obrigatórios \\
\hline 2. Quais elementos podem ocorrer? & Opcionais \\
\hline 3. Onde os elementos devem ocorrer? & Sequência Esperada \\
\hline 4. Onde os elementos podem ocorrer? & Sequência Possível \\
\hline 5. Com que frequência os elementos podem ocorrer? & $\begin{array}{l}\text { Iterativos ou } \\
\text { Recursivos }\end{array}$ \\
\hline
\end{tabular}

Quadro 3: elementos do contexto de configuração

Em algumas situações de investigação linguística, o uso proposto desses elementos funcionais pode enrijecer o que é denominado de EEG. Por um lado, há apropriações dessa abordagem desprovidas de críticas, como a realizada por Gouveia (2008: 117), ao afirmar que a análise da realização da EPG “terá que ser feita em função não de uma estrutura fixa e rígida, mas de um potencial, o potencial de estrutura genológica”. Por outro lado, críticas são ancoradas no fato da potencialidade anunciada resultar na determinação dos estágios integrantes da macroestrutura textual, invisibilizando o caráter probabilístico da linguagem. A EPG é ignorada nas propostas de Eggins e Martin (cf. EGGINS, 2004; EGGINS; MARTIN, 1997; MARTIN, 2001, 1997).

A não obrigatoriedade dos elementos ou estágios também corrobora para a caracterização da identidade genérica, diferentemente do proposto por Hasan (1996, 1989). O dinamismo é característico das línguas naturais e com os gêneros textuais não é diferente, independentemente da estabilidade constitutiva das diversas formas de participação nas interações do cotidiano, as quais são construídas por atores sociais com diferentes papéis nas práticas culturais. Nessa perspectiva, críticas à EPG foram reunidas em dois aspectos por Motta-Roth e Heberle (2005: 27) a partir de trabalhos de Eija Ventola e James Robert Martin, respectivamente: (i) a EPG seria "uma abstração sem correspondência aos dados da linguagem real"; e (ii) a EPG imporia "uma visão linear e objetiva de gêneros, o que a coloca como uma categoria desconectada do evento que lhe deu origem" ${ }^{18}$.

${ }^{18}$ Martin e Rose (2007: 309) salientam que os elementos obrigatórios seriam determinados pelo registro de campo e a presença dos elementos opcionais pelas variáveis de relação e modo, conforme Ruqaiya Hasan. Os autores caracterizam tal abordagem como mode- 
Os gêneros característicos da instituição publicitária ilustrariam bem a relevância dos elementos opcionais, os quais, quase sempre, são imprevisíveis ou funcionam como surpresas, ainda que tal ocorrência seja esperada pelo consumidor. Esses elementos surpresas seriam, então, obrigatórios nos gêneros dessa instituição? Nas pesquisas sobre o gênero relatório de estágio supervisionado, coordenadas pelo primeiro autor deste artigo (cf. SILVA, 2013, 2012b, 2012c; SILVA; FAJARDO-TURBIN, 2012, 2011; SILVA; MENDES, 2012), as referidas categorizações orientaram a análise genérica, porém, não foram utilizadas com o 'rigor' proposto em Hasan $(1996,1989)$, pois os estágios integrantes dos relatórios são bastante instáveis, reflexo do próprio trabalho desenvolvido na formação inicial de professores nas disciplinas de estágio supervisionado obrigatório, nas licenciaturas focalizadas. Nessa situação, tal orientação motivaria a identificação imprecisa e bastante ampla dos estágios do gênero, resultando no que Eggins (2004: 61) e Matthiessen (2013: 4) denominam, respectivamente, de rótulos funcionalmente vazios e generalizações óbvias, como as denominações introdução/início, desenvolvimento/meio, conclusão/fim, comuns a quaisquer gêneros textuais.

Além das convergências e divergências teóricas entre as propostas confrontadas nesta seção, sintetizamos uma divergência teórica já pontuada na literatura brasileira sobre o assunto (VIAN JR.; LIMA-LOPES, 2005; VIAN, JR., 1997). Está relacionada ao ponto de partida da análise textual dentro da abordagem sistêmico-funcional. O contexto de situação, por meio das variáveis de registro, é o ponto de partida da abordagem do texto proposta por Ruqaiya Hasan, ao passo que James Robert Martin considera o contexto de cultura, portanto, o gênero, como parâmetro indispensável para análise textual. Para esse último autor, "é o gênero que pré-seleciona as variáveis de registro, associando-as a partes específicas da estrutura textual, a chamada estrutura esquemática" (VIAN JR.; LIMA-LOPES, 2005: 34), ou seja, quaisquer constituintes da micro e macroestrutura linguística são focalizados

\footnotetext{
lo axial, opondo-o ao modelo interestratal assumido por eles. Nessa perspectiva, teríamos uma relação entre registro e gênero que se daria no sentido de um eixo, horizontalmente, e outra que se daria entre diferentes estratos, verticalmente. Os autores não fazem referência a algum estudo específico desenvolvido pela autora para fundamentar a totalidade dessas ponderações, as quais ignoramos parcialmente.
} 
dentro da abstração característica do contexto de cultura em que as interações sociais ocorrem (Figura 2).

Finalmente, a revisão da literatura permite-nos destacar a existência de duas perspectivas de investigação dos gêneros dentro da abordagem aqui identificada como clássica, a qual também aponta para a abordagem tipológica a ser focalizada. Um ponto de entrada seria a macroestrutura do texto, pela identificação do que se denomina de EPG ou, de forma mais ampla, EEG. Outro ponto de entrada seria pela microestrutura do texto, por meio da descrição léxico-gramatical, orientada pelas metafunções da linguagem e pelas variáveis de registro. Assim, as categorias de gênero e registro podem estar bastante imbricadas na LSF, dependendo da perspectiva investigativa assumida. Na próxima seção, continuamos descrevendo uma perspectiva teórica bastante próxima dessa última, na qual é adicionado o desempacotamento da estrutura semântica como procedimento analítico diferenciado.

\section{PERSPECTIVA TIPOLÓGICA DOS GÊNEROS TEXTUAIS}

O principal idealizador da abordagem tipológica dos gêneros textuais é Christian M. I. M. Matthiessen. Nessa abordagem, a denominação tipo textual é utilizada pelo autor com mais frequência, em detrimento da nomenclatura gênero textual por nós assumida neste artigo (cf. HALLIDAY; MATTHIESSEN, 2013, 2004; MATTHIESSEN; TERUYA; LAM, 2010). Talvez, tal preferência do autor seja justificada pelo pressuposto da concepção de texto enquanto unidade de análise desde os primórdios da LSF, quando a noção de gênero ainda estava bastante atrelada aos estudos literários. Optamos pela nomenclatura gênero textual para evitar alguma confusão ou sobreposição terminológica com a noção de tipologia ou sequência textual (argumentação, descrição, exposição, injunção, narração), assimilada amplamente nos estudos brasileiros da Linguística Textual (LT), tendo Ingedore B. V. Koch e Luiz Antônio Marcuschi como principais idealizadores (cf. KOCH, 2004; MARCUSCHI, 2008) ${ }^{19}$.

${ }^{19}$ Reproduzimos aqui a definição de texto apresentada por Jean-Michel Adam (2009: 129), um dos principais influenciadores da abordagem dos gêneros textuais, proposta por Ingedore B. V. Koch e Luiz Antônio Marcuschi no Brasil: “TEXTO é uma estrutura hierár- 
As pesquisas desenvolvidas na LSF parecem ignorar essa noção de tipologia textual. No contexto brasileiro, Silva (2012c: 291) ensaia um diálogo explícito entre a LT e a LSF para alcançar o enfoque da unidade textual do gênero relatório de estágio supervisionado, evitando análises linguísticas restritas ao nível das orações gramaticais. O autor se utilizou exatamente da articulação entre diferentes tipologias ou sequências textuais como uma das portas de entrada para a análise do gênero. Ainda recordamos de algumas tentativas de agrupamento de textos por semelhanças ou diferenças linguísticas, como a organização de gêneros em rede de sistema, apresentada por Martin (2001: 290) a partir do que o autor denominou de perspectivas tipológica e topológica. Tais iniciativas correspondem a esforços para suprir o esvaziamento de categorias analíticas que ainda parece pairar sobre as noções teóricas de gênero textual e de contexto de cultura na LSF, mesmo com as constantes inovações delineadas.

De forma bastante ampla, os gêneros textuais podem ser concebidos nesta abordagem enquanto processos sociais realizados institucionalmente, marcados por contextos culturais específicos. A noção de instituição é definida como ambiente ou domínio social em que textos são realizados com características e objetivos particulares. Os ambientes correspondem a atividades sociais em grupos específicos, a exemplo da instituição familiar, instituição escolar, instituição publicitária, dentre outras. As instituições são organizadas por diferentes situações interativas, ou seja, os gêneros textuais (MATTHIESSEN, 2007).

Para descrição da referida abordagem, retomamos a representação da perspectiva global da linguagem - Figura 1. Inicialmente, precisamos visualizar uma matriz de instanciação-estratificação a partir do cruzamento entre (i) a hierarquia de estratificação e (ii) a escala de instanciação, a partir do encontro entre as retas em qualquer ponto de intersecção (MATTHIESSEN; HALLIDAY, 2009: 82; HALLIDAY, 1995: 215). Algumas pesquisas tendem a focalizar pontos isolados dessa matriz, como as desenvolvidas na Linguística de Corpus, que, frequentemente, usam ferramentas computacionais para in-

quica complexa que compreende n sequências - elípticas ou completas - do mesmo tipo ou de tipos diferentes" - narrativa; descritiva; argumentativa; explicativa; conversacionaldialogal (maiúsculas do autor). 
vestigar a região compreendida pelos estudos léxico-gramaticais, tendendo a desconsiderar os demais estratos de organização da linguagem ${ }^{20}$. Quando a atenção do analista é direcionada apenas a um polo da escala de estratificação, sem a complementação da análise linguística com outras perspectivas, é impossível estabelecer generalizações sobre a língua investigada ou, até mesmo, a respeito do gênero focalizado.

A investigação linguística a partir de gêneros, localizados no meio da escala de instanciação, permite o enfoque da materialidade textual no contexto de situação. Para Matthiessen, Kazuhiro e Wu (2008), os gêneros são instâncias ou realizações atreladas a um dado sistema, passíveis de observação, análise e descrição. Quando aproximados do polo potencial da escala de instanciação, os gêneros são vistos como conjuntos de registros, sendo possível generalizar os usos das formas linguísticas no sistema.

O desencontro da (i) hierarquia de estratificação e da (ii) escala de instanciação levou Matthiessen (2007) a propor a tipologia textual baseada em contexto, no âmbito dos estudos sistêmico-funcionais. Quando investigamos a gramática da língua com o intuito de fazer generalizações sobre essa língua $^{21}$, essas devem incluir observações sobre o que é encontrado nos textos a partir de um ângulo que permita ao analista se mover na escala de instanciação, passando por instâncias observáveis em direção ao sistema, o qual se configura como realizações estáveis de traços linguísticos característicos

${ }^{20}$ A Linguística de Corpus fornece ferramentas analíticas que contribuem para os estudos linguísticos desenvolvidos ao longo da matriz de instanciação-estratificação, auxiliando nas pesquisas que envolvem grandes quantidades de dados, envolvendo, inclusive, gêneros textuais, o que impossibilitaria análises manuais.

${ }^{21}$ Conforme Matthiessen (2001: 01), "quando usamos a língua, engajamo-nos com a gramática em forma de texto. Quando aprendemos uma língua, encontramos a gramática em forma de texto, e 'destilamos' os sistemas gramaticais desses encontros. E, quando investigamos a gramática, observamo-la em forma de texto - como padrões de palavras que se desdobram no tempo em específicos contextos. (Padrões de palavras são padrões de itens gramaticais ('palavras funcionais') e itens lexicais ('palavras de conteúdo') que formam as estruturas gramaticais.)" / "When we use language, we thus engage with grammar as text. When we learn language, we encounter grammar as text, and we "distil" the grammatical system out of these encounters. And when we investigate grammar, we observe it as texts - as patterns of wording unfolding in time within some specific context. (Patterns of wording are patterns of grammatical items ("function words") and lexical items ("content words") forming grammatical structures.)”. 
de diferentes situações interativas. Se a ideia é transitar da instância ao sistema, onde o pesquisador deve parar? A resposta está condicionada ao objetivo de pesquisa por ele delineado: "qualquer ponto que cruze a escala de instanciação é, em princípio, um foco válido para investigação” (MATTHIESSEN, 2007: 1).

Investigações localizadas no meio da escala de instanciação correspondem a análises de texto passíveis de generalização sobre o gênero textual investigado, conforme trabalho realizado por Ghadessy (1993), ao compilar um livro cobrindo diversos aspectos de análise de registro. $\mathrm{O}$ autor incluiu um trabalho em que investigou a natureza da escrita para negócios com base em um corpus de grande dimensão com vistas a estabelecer características linguísticas identificadoras da carta de negócios. Esses exemplares do gênero foram descritos numa cadeia de eventos comunicativos, realizados como cartas com determinada estrutura organizacional.

Investigações desse tipo também adotam uma abordagem baseada em sistema, envolvendo descrição de subsistemas de registros, ou seja, realizações textuais pontuais, como o trabalho realizado por Halliday (1973), ao analisar o discurso de crianças até o completo desenvolvimento na fase adulta, levando o autor a formular princípios relacionados à estrutura interna da língua e aos contextos sociais dentro dos quais o discurso investigado opera.

Christian M. I. M. Matthiessen propõe descrições de subsistemas de registros por meio de generalizações originárias da análise textual em grande escala. $\mathrm{O}$ funcionamento de um constituinte gramatical pode ser selecionado para investigação em diferentes gêneros, considerando os processos sociossemióticos que atravessam a materialidade textual, conforme discutido mais adiante. Ou seja, diferentemente da abordagem clássica dos gêneros textuais, o autor situa o registro no centro das investigações na LSF. Para o autor, o fortalecimento da teoria de registro é muito importante, sendo necessário desenvolver mais estudos descritivos de registros, vinculados a diferentes instituições na sociedade.

$\mathrm{Na}$ abordagem tipológica, Matthiessen $(2007,1993)$ apresenta a noção de Cartografia de Registro, a qual se desdobra num processo que poderá preencher os 'vazios' descritivos de pesquisas sobre língua em contexto, confor- 
me mencionamos na seção Percursos paralelos - LSF/LA, deste artigo. De acordo com o autor, esses 'vazios' podem ser observados na intersecção do cruzamento da (i) hierarquia de estratificação e da (ii) escala de instanciação. Pesquisas linguísticas localizadas no espaço entre sistema e instância precisam ser realizadas. Essas investigações podem ser realizadas (a) pelo viés da descrição da língua, abordando o polo do sistema, descrevendo os subsistemas dos gêneros com base nas descrições existentes do sistema de referência; (b) pelo viés analítico-textual, abordando o polo da instância para, posteriormente, fazer generalizações com base em resultados obtidos de análises previamente existentes. Quando fazemos uso da hierarquia de estratificação, precisamos relacionar padrões do contexto de situação (registro - campo, relação e modo) com padrões semânticos, o que acontece pelo desempacotamento da estrutura semântica.

Ao focalizarmos a interface entre língua e contexto pelos padrões léxico-gramaticais, identificamos ferramentas para uma investigação semântica. A configuração semântica do gênero também demanda a mobilização das variáveis do contexto de situação, tornando-se possível caracterizar os estágios componentes do gênero. Assim, temos aqui uma interferência da abordagem clássica dos gêneros, pois podemos descrever como os elementos da EPG ou os estágios da EEG são realizados semanticamente ou, até mesmo, discursivamente.

O texto é uma unidade de sentido, informado semanticamente por três significados atrelados às metafunções da linguagem. Temos um texto construído por estágios e por metafunções. A relação entre as duas formas de criação de significado é indireta, sendo mediada pela semântica. Em outros termos, a relação entre texto e contexto é passível de observação pelo estrato semântico, responsável pela construção de significados. Matthiessen (2007) propõe que se olhe a estrutura textual interna com vistas "de cima", ou seja, do ponto de vista do contexto, e este, por sua vez, do ponto de vista semântico, ou seja, do "em torno" - através das estratégias semânticas que são características da língua em um determinado contexto. Dessa maneira, adotamos uma visão intermediária em termos da escala de instanciação, possibilitando-nos explorar como a gramática opera em relação às estruturas esquemáticas características dos gêneros. 
Desenvolvendo esta abordagem tipológica, Matthiessen, Teruya e Wu (2008) propõem um tipo de mapeamento para análise textual, denominado de Tipologia Textual Baseada em Contexto, aqui representada pela Figura 4 (ver Anexo), adaptada de Matthiessen, Teruya e Lam (2010: 221) e denominada de Círculo Discursivo. Trata-se de uma tipologia textual orientada pelas metafunções da linguagem, acomodando parâmetros contextuais de registro. Ao propor esse arcabouço teórico, os autores se apoiaram no trabalho inédito de uma das pioneiras em LSF - Jean Ure. O mapeamento está localizado no espaço central da matriz de instanciação-estratificação, onde justamente acontecem as variações de registro. Este arcabouço tem como base as instituições sociais, isto é, os tipos de situações ou atividades interativas características de determinados contextos culturais. As instituições envolvem tipos de situações agregadas onde os gêneros são realizados.

Para a tipologia textual baseada em contexto, Matthiessen, Teruya e Lam (2010: 221) adotam diretamente as variáveis de modo e de campo, integrantes das variáveis de registro. Para o modo, duas outras variáveis são levadas em consideração: (a) meio, envolvendo as modalidades escrita e falada da língua, bem como as variantes dessas modalidades, a exemplo dos textos escritos para serem falados, além das implicações originárias do canal de realização da linguagem (gráfico, eletrônico, outros); e (b) turno: mesmo considerando a natureza dialógica da linguagem, consideram-se aqui as efetivas possibilidades de troca de turno na circulação do gênero, o que resulta nas subcategorias de monólogo ou diálogo. Nas palavras de Gouveia (2008: 113), lembramos que "texto é tudo o que produzimos quando comunicamos, podendo o mesmo ser falado ou escrito. Da mesma forma, um texto pode ser de um autor ou de vários, isto é, pode ser de produção individual (uma carta, um relatório) ou de produção coletiva (uma conversa, um debate)".

Para facilitar a compreensão do leitor, no Quadro 4 reproduzimos uma síntese da tipologia textual baseada em contexto, com alguns exemplos de gêneros. Como representado no círculo discursivo (Figura 4 - Anexo), lembramos ainda que os gêneros foram dispostos conforme os processos sociais predominantemente presentes. Tais processos misturam-se na composição dos gêneros, mesmo havendo alguma predominância. 


\begin{tabular}{|c|c|c|c|c|c|}
\hline \multicolumn{2}{|l|}{ MEIO } & \multicolumn{2}{|l|}{ ESCRITO } & \multicolumn{2}{|l|}{ FALADO } \\
\hline CAMPO & TURNO & MONÓLOGO & DIÁLOGO & DIÁLOGO & MONÓLOGO \\
\hline \multicolumn{2}{|l|}{ EXPOR } & $\begin{array}{l}\text { Artigo } \\
\text { acadêmico } \\
\text { Verbete }\end{array}$ & $\begin{array}{l}\text { Avaliação } \\
\text { Notificação }\end{array}$ & $\begin{array}{l}\text { Debate } \\
\text { Monitoria }\end{array}$ & $\begin{array}{l}\text { Documentário } \\
\text { Palestra }\end{array}$ \\
\hline \multicolumn{2}{|c|}{ REPORTAR } & $\begin{array}{l}\text { Biografia } \\
\text { Reportagem }\end{array}$ & Questionário & $\begin{array}{l}\text { Entrevista } \\
\text { Interrogatório }\end{array}$ & Depoimento \\
\hline \multicolumn{2}{|c|}{ RECRIAR } & $\begin{array}{l}\text { Romance } \\
\text { Fábulas }\end{array}$ & $\begin{array}{l}\text { Embolada } \\
\text { Wiki ficção }\end{array}$ & $\begin{array}{l}\text { Novela } \\
\text { Peça de teatro }\end{array}$ & $\begin{array}{l}\text { Comentário } \\
\text { radiofônico } \\
\text { Anedota }\end{array}$ \\
\hline \multicolumn{2}{|c|}{ COMPARTILHAR } & $\begin{array}{l}\text { Blog } \\
\text { Diário }\end{array}$ & $\begin{array}{l}\text { E-mail pessoal } \\
\text { SMS }\end{array}$ & $\begin{array}{l}\text { Fofoca } \\
\text { Conversa }\end{array}$ & $\begin{array}{l}\text { Memórias } \\
\text { Testemunho }\end{array}$ \\
\hline \multicolumn{2}{|c|}{ REALIZAR } & $\begin{array}{l}\text { Lista de } \\
\text { compras }\end{array}$ & $\begin{array}{l}\text { Convite } \\
\text { Carta de } \\
\text { negócios }\end{array}$ & $\begin{array}{l}\text { Prestação de } \\
\text { serviço } \\
\text { Colaboração }\end{array}$ & $\begin{array}{l}\text { Cerimônia } \\
\text { (batismo, } \\
\text { casamento) }\end{array}$ \\
\hline \multicolumn{2}{|c|}{ RECOMENDAR } & $\begin{array}{l}\text { Propaganda } \\
\text { Sinopse }\end{array}$ & $\begin{array}{l}\text { Carta promo- } \\
\text { cional } \\
\text { Carta de } \\
\text { aconselhamento }\end{array}$ & $\begin{array}{l}\text { Conselho } \\
\text { Aviso }\end{array}$ & $\begin{array}{l}\text { Súplica } \\
\text { Sermão } \\
\text { religioso }\end{array}$ \\
\hline \multicolumn{2}{|c|}{ HABILITAR } & $\begin{array}{l}\text { Contrato } \\
\text { Receita }\end{array}$ & Exortação & Demonstração & $\begin{array}{l}\text { Procedimento } \\
\text { Regulamento }\end{array}$ \\
\hline \multicolumn{2}{|c|}{ EXPLORAR } & $\begin{array}{l}\text { Relato } \\
\text { investigativo } \\
\text { Resenha }\end{array}$ & $\begin{array}{l}\text { Carta ao editor } \\
\text { Desafio }\end{array}$ & $\begin{array}{l}\text { Discussão } \\
\text { Debate }\end{array}$ & $\begin{array}{l}\text { Discurso } \\
\text { político }\end{array}$ \\
\hline
\end{tabular}

Quadro 4: processos sociais em texto

No tocante à variável de campo, apenas a natureza do processo sociossemiótico é investigada, isto é, o que está acontecendo. Em princípio, todos os processos semióticos são sociais, todavia, podemos entender alguns como sendo essencialmente sociais, enquanto outros que vem a ser intrinsicamente semióticos e sociais. Os primeiros processos não necessitam da linguagem verbal para serem realizados, os últimos não somente realizam atividades sociais, mas, ao mesmo tempo, constroem significados via linguagem verbal. Esta distinção entre processos essencialmente sociais e processos sociossemióticos mediados pela linguagem verbal foi motivada pela distinção, respecti- 
vamente, entre categorias do contexto de primeira e de segunda ordem feita por Halliday (1978) para sistematizar a organização da língua. As categorias de primeira ordem existem independentemente da língua. As categorias de segunda ordem só acontecem por meio da língua, a exemplo da produção de blogs para compartilhar experiências, sentimentos ou valores em ambientes virtuais. Conforme destacado por Matthiessen (2013: 8), há estágios organizadores dos gêneros que são realizados como atividades físicas nas práticas sociais, portanto, como categorias de primeira ordem, e não são, necessariamente, realizados na materialidade textual, como categorias de segunda ordem. A interação entre uma equipe de remo dentro do barco ilustra o contexto de primeira ordem, pois a colaboração pela linguagem verbal é mínima durante uma regata. Ou seja, a interação entre uma equipe de remo dentro do barco se dá em grande parte por meio da linguagem corporal, uma semiose não verbal.

O processo essencialmente social é de o "realizar", já os processos sociais e semióticos são os de "significar". Há, então, um tipo primário de processo social em campo, a saber, realizar, e sete tipos primários de processos de significar: expor; reportar; recriar; compartilhar; realizar; recomendar; habilitar; e explorar. Os secundários são advindos da subclassificação destes oito processos sociossemióticos. Todos estão representados na esfera de atividades sociossemióticas ilustrada no círculo discursivo (Figura 4 - Anexo). No Quadro 5, descrevemos os oito tipos primários de processos sociossemióticos com os quais os indivíduos se associam a fim de atingir propósitos em contextos específicos.

\begin{tabular}{|l|l|}
\hline $\begin{array}{l}\text { PROCESSO } \\
\text { SOCIOSSEMIÓTICO }\end{array}$ & DESCRIÇÃO \\
\hline Expor & $\begin{array}{l}\text { Explanar sobre a classificação de fenômenos em geral } \\
\text { com base em saberes (especializados ou não) por meio } \\
\text { de taxonomia ou exposição. }\end{array}$ \\
\hline Reportar & $\begin{array}{l}\text { Relatar sobre a ocorrência ou existência de algo den- } \\
\text { tro do domínio da experiência, por meio de narrativa, } \\
\text { pesquisa ou catalogação. }\end{array}$ \\
\hline Recriar & $\begin{array}{l}\text { Recriar experiências tipicamente fictícias por meio de } \\
\text { narrativas ou dramatizações. }\end{array}$ \\
\hline Compartilhar & $\begin{array}{l}\text { Compartilhar ou dividir experiências, sentimentos e } \\
\text { valores a fim de calibrar relações humanas. }\end{array}$ \\
\hline
\end{tabular}




\begin{tabular}{|l|l|}
\hline Realizar & $\begin{array}{l}\text { Fazer ou executar atividades sociais. A língua auxilia o } \\
\text { desenrolar das atividades. }\end{array}$ \\
\hline Recomendar & $\begin{array}{l}\text { Recomendar ações ou aconselhar participantes da in- } \\
\text { teração em função de uma ação futura. }\end{array}$ \\
\hline Habilitar & $\begin{array}{l}\text { Habilitar alguém a fazer algum tipo de atividade por } \\
\text { meio de instrução ou por meio de regulamentação. }\end{array}$ \\
\hline Explorar & $\begin{array}{l}\text { Explorar valores, ideias ou indícios, tipicamente em } \\
\text { público com o intuito de comparar opções alternativas } \\
\text { e arguir a favor do posicionamento construído. }\end{array}$ \\
\hline
\end{tabular}

Quadro 5: processos sociossemióticos

Esses processos sociossemióticos compreendem o conteúdo tematizado no texto e, principalmente, as atividades sociais realizadas pelos usuários da língua em contextos. O nível semântico-discursivo é adotado como o ponto de entrada para analisar a língua realizada no contexto de situação. O contexto de cultura continua no nível mais abstrato da hierarquia da estratificação, enquanto o nível semântico-discursivo opera no estrato do contexto de situação, estando, por sua vez, diretamente articulado às metafunções da linguagem. A abordagem tipológica contribui para a descrição de registros ou gêneros em função da exploração do sistema gramatical da língua. Mantendo-se firme à proposta original de Halliday (1978), Matthiessen (2007) sugere a descrição da gramática de qualquer língua com vistas 'de cima' (visão contextual), utilizando-se do conceito da (i) hierarquia de estratificação para investigar a gramática, sem perder de vista os aspectos textuais e contextuais. Porém, ao mesmo tempo, focando no espaço mediano da (ii) escala de instanciação, propõe a descrição linguística de diferentes gêneros textuais, possibilitando a apresentação de padrões de variação de registro. Portanto, tais padrões estão correlacionados a características linguísticas (discursivas, semânticas, léxico-gramaticais, fonológicas ou grafológicas) do texto em contextos.

Para finalizar, a título de ilustração de pesquisa brasileira realizada a partir da perspectiva tipológica dos gêneros, mencionamos o trabalho desenvolvido por Gysel (2013), ao traçar o perfil ideacional de blogs com propósito de explorar a relação entre processos sociossemióticos e os padrões gramaticais de transitividade no texto do gênero ${ }^{22}$. Os dados foram comparados para iden-

${ }^{22}$ Esta pesquisa foi orientada pela Profa. Dra. Maria Lúcia Vasconcelos (UFSC) e coorientada pela segunda autora deste artigo. 
tificar diferenças e semelhanças nas configurações de texto e de contexto dos blogs produzidos em português brasileiro e em inglês americano. Em outras palavras, foram investigados apenas blogs com propósito de verificar como os textos do gênero compartilhavam experiências. A investigação foi desenvolvida em duas perspectivas interconectadas: segmentação textual para encontrar outros processos sociossemióticos que realizavam o blog; e análise dos processos de transitividade vinculada à realização dos processos sociossemióticos.

Os Gráficos 1 e 2 reproduzidos adiante mostram que os blogs são realizados a partir da predominância de processos material, mental e relacional, resguardadas algumas variações da recorrência dos processos no par de línguas investigado. A ocorrência desses processos é justificada pelo compartilhamento de experiências, sentimentos ou valores, possibilitados pelo gênero e vivenciados pelo blogueiro. A comparação possibilitou a explicitação de realizações gramaticais diferenciadas, motivadas, provavelmente, pelos contextos de origem, podendo servir como parâmetros na formação de tradutores.

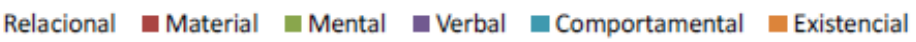

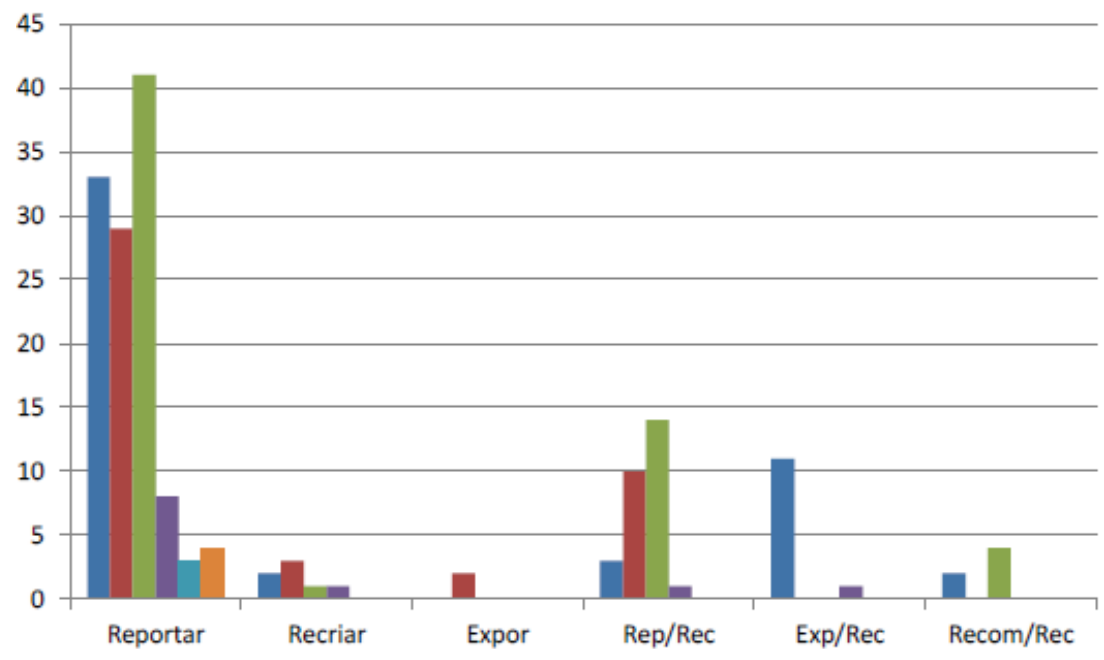

Gráfico 1: blog - português brasileiro (GYSEL, 2013: 201) 


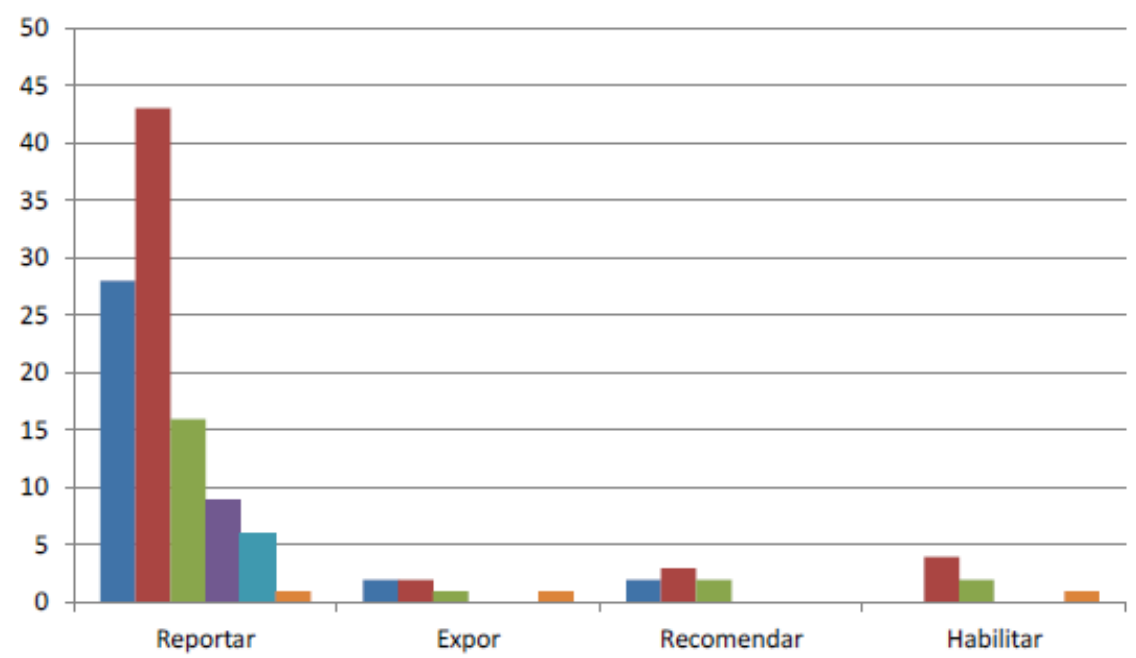

Gráfico 2: blog - inglês americano (GYSEL, 2013: 205)

Os gráficos apresentam a realização dos tipos de processo do sistema da transitividade no gênero blog, escrito em dois idiomas - português brasileiro (Gráfico 1) e inglês americano (Gráfico 2). Além de compartilhar, o gênero também tende a realizar outros tipos de processos sociossemióticos que foram investigados por meio da análise dos processos do sistema de TRANSITIVIDADE. Os resultados apontaram para a realização dos processos sociossemióticos de reportar, realizado principalmente por processos mentais, como pode ser visto no Gráfico 1 - português brasileiro. Para os textos em inglês americano (Gráfico 2), a configuração muda um pouco. Em termos dos processos do sistema de TRANSITIVIDADE, foi constatado que, além de compartilhar, os textos tendem a reportar experiências através da realização de processos materiais. A diferença observada na pesquisa pode ser explicada pelo fato do blog em português fazer reflexões sobre os participantes e as ações por eles realizadas. Em contrapartida, o blog em inglês americano constrói significado enfatizando as ações e as reações dos participantes enquanto foco dos relatos nos textos investigados. 


\section{CONSIDERAÇÕES FINAIS}

Neste artigo, despendemos esforços para apresentar nossa leitura crítico-descritiva da abordagem dos gêneros textuais na LSF, evitando a supervalorização de alguma perspectiva teórica em detrimento de outra. Com esta revisão da literatura e considerando a própria vitalidade da teoria, intencionamos construir com o leitor possibilidades de enfoques para as futuras pesquisas científicas envolvendo gêneros textuais, a partir dos constructos teórico-metodológicos desenvolvidos ao longo de aproximadamente seis décadas de existência da LSF.

Qualquer teoria científica está sujeita a críticas, o que não é diferente com a LSF. Na proporção em que teorias trazem respostas para as demandas sociais e, consequentemente, para as "disciplinas" de referência, novas perguntas são geradas num processo ininterrupto. Para a LA, a abordagem sistêmico-funcional contribui de forma bastante significativa ao possibilitar o enfoque de problemas sociais em diversas instituições ou domínios sociais, a partir da análise da materialidade textual em contexto, tomando como referência o sistema produzido para descrição ou análise linguística.

As categorias de análise textual demonstram a eficácia da LSF, mas também evidenciam o risco de redução das análises linguísticas a aspectos formais da língua. Essa tendência foi observada nas perspectivas teóricas de análise de gêneros textuais discutidas no artigo. No território brasileiro, considerando os encaminhamentos práticos a partir dos resultados teóricos produzidos nas pesquisas em LA, em especial, para situações de ensino, a supervalorização de aspectos formais, provavelmente, não responderia às demandas do trabalho com gêneros textuais nos contextos pedagógicos, seja na formação de professores ou de alunos na educação básica. Esse encaminhamento poderia resultar no trabalho escolar com estruturas textuais rígidas, ignorando o empoderamento discente instaurado pela inserção dos aprendizes em situações interativas reais, orientadas por práticas de letramento significativas.

Os gêneros textuais são produzidos para objetivos específicos nas práticas sociais da vida diária, conforme evidenciamos a partir das duas perspectivas teóricas focalizadas neste artigo. Uma teoria linguística proposta para 
caracterizar os gêneros precisa oferecer ferramentas analíticas que possibilitem a apreensão do dinamismo das práticas sociais. Nessa perspectiva, acreditamos que a noção de contexto de cultura precisa ser explorada ou, até mesmo, desdobrada, na abordagem sistêmico-funcional, de maneira que compreendamos como atores sociais de naturezas diversas, originários de instituições socioculturais, interferem nas formas padronizadas de interação pela linguagem.

Finalmente, salientamos que a abordagem transdisciplinar de investigação científica na LA pode auxiliar na descrição do contexto de cultura, a partir do diálogo com diferentes "disciplinas" do conhecimento por meio de diferentes categorias analíticas. Tal diálogo se torna ainda mais significativo quando compreendemos que os estágios, organizadores dos processos sociais caracterizadores dos gêneros, nem sempre se configuram na materialidade linguística ou estruturas textuais, mas, também, em outras ações integrantes das atividades sociais características de diferentes culturas. ${ }^{23}$

${ }^{23}$ Finalmente, agradecemos às pessoas que, direta ou indiretamente, auxiliaram-nos na produção deste artigo. Precisamos nomear aqui Adair Vieira Gonçalves, Lívia Chaves de Melo e Rodrigo Esteves de Lima-Lopes, pela leitura crítica, e Marcelo Baldissera, pela contribuição com as figuras criadas. O conteúdo do artigo, porém, é da nossa inteira responsabilidade. 


\section{ANEXO}

Figura 4: círculo discursivo

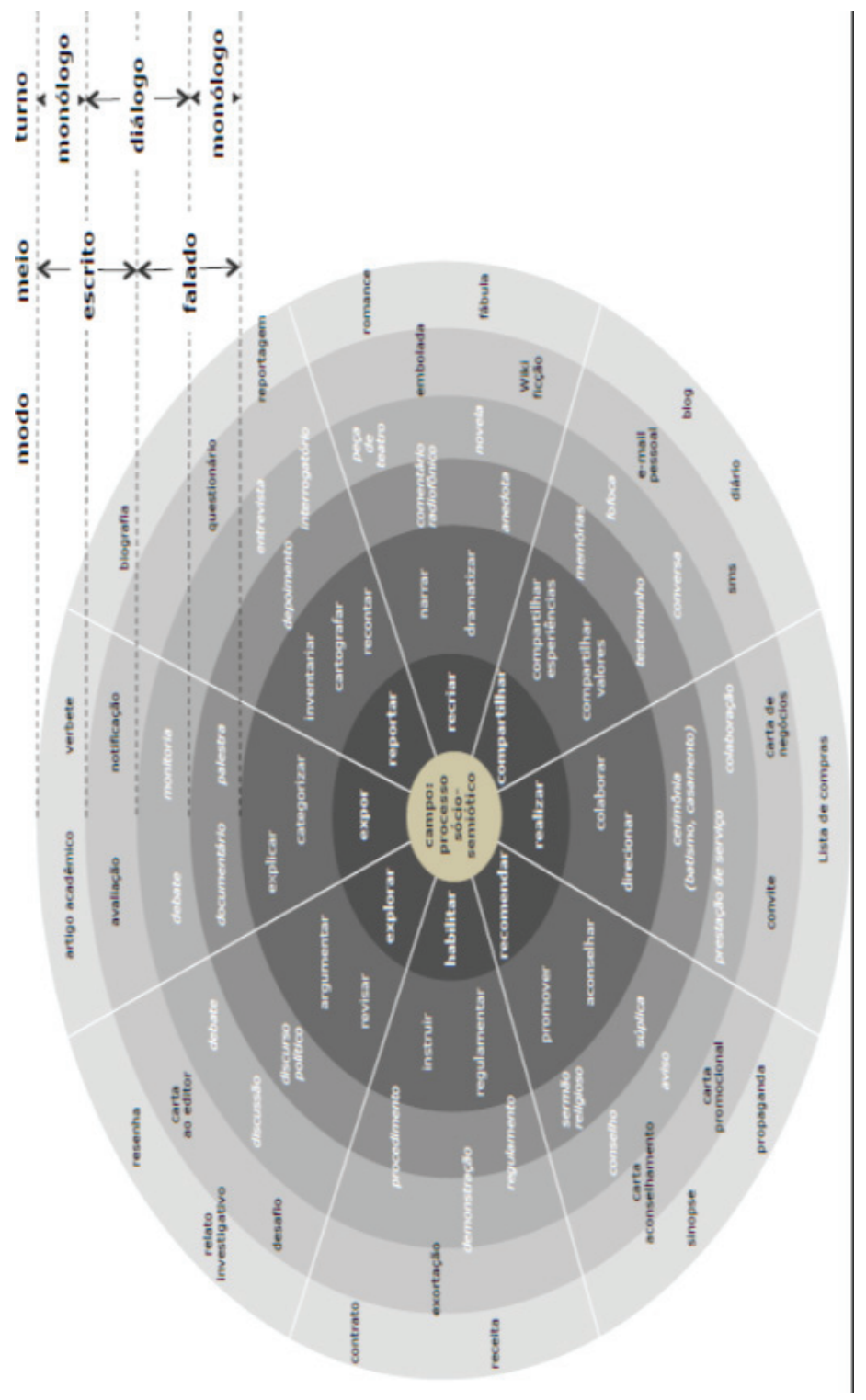




\section{REFERÊNCIAS BIBLIOGRÁFICAS}

ADAM, Jean-Michel. Quadro teórico de uma tipologia sequencial. In: BEZERRA, B. G.; BIASI-RODRIGUES, B.; CAVALCANTE, M. (Org.). Gêneros e sequências textuais. Recife: Editora da Universidade de Pernambuco - EDUPE, 2009. p. 115-132.

APARÍCIO, Ana. Modos individuais e coletivos de produzir a inovação no ensino de gramática em sala de aula. In: Revista Brasileira de Linguística Aplicada. Belo Horizonte: UFMG/ALAB, v. 10, n. 4, p. 883-907, 2010.

ARAÚJO, Cristiano. O sistema semântico de PROJEÇÃO e sua dispersão gramatical em português brasileiro: uma descrição sistêmico-funcional orientada para os estudos linguísticos da tradução. Belo Horizonte, 2007. 133 p. Dissertação (Mestrado em Estudos Linguísticos) - Faculdade de Letras da Universidade Federal de Minas Gerais, Belo Horizonte, 2007.

BAKHTIN, Mikhail. The Problem of Speech Genres. In: Speech Genres \& Other Late. Essays. Translated by Vern W. Mcgee. Austin: University of Texas Press. 1986. p. 60-102.

BARBARA, Leila; MOYANO, Estela. (Org.). Textos e linguagem acadêmica: explorações sistêmico-funcionais em espanhol e português. Campinas: Mercado de Letras, 2011.

BORGES, Flávia. Os gêneros textuais em cena: uma análise crítica de duas concepções de gêneros textuais e sua aceitabilidade na educação no Brasil. In: Revista Brasileira de Linguística Aplicada. Belo Horizonte: UFMG/ALAB. v. 12, n. 1, p. 119-140. 2012.

BOWCHER, Wendy; SMITH, Bradley (Ed.). Systemic Phonology: Recent Studies in English. United Kingdom: Equinox Publishing Ltd, 2013 
BRASIL. Ministério da Educação/Secretaria de Educação Básica. Orientações Curriculares para o Ensino Médio: Linguagem, Códigos e suas Tecnologias. Brasília, 2006.

. Ministério da Educação. Parâmetros Curriculares Nacionais. Língua portuguesa: Ensino Médio. Brasília, 2000.

. Ministério da Educação/Secretaria de Educação Fundamental. Parâmetros Curriculares Nacionais. Língua portuguesa: Ensino Fundamental II (Terceiro e Quarto Ciclos). Brasília, 1998a.

. Parâmetros Curriculares Nacionais. Língua estrangeira: Ensino Fundamental II (Terceiro e Quarto Ciclos). Brasília: Ministério da Educação/ Secretaria de Educação Fundamental, 1998b.

. Ministério da Educação/Secretaria de Educação Fundamental. Parâmetros Curriculares Nacionais. Língua portuguesa: Ensino Fundamental I ( $1^{\text {a }}$ a $4^{\text {a }}$ série). Brasília, 1997.

CELANI, Maria. A. Afinal, o que é Linguística Aplicada?. In: PASCHOAL, M.;

CELANI, M. (Org.). Linguística Aplicada: da Aplicação da Linguística à Linguística Transdisciplinar. São Paulo: Educ. 1992. 15-23.

CHRISTIE, Frances; DEREWIANKA, Berewianka. School Discourse. London: Continuum, 2008.

DORNELLES, Clara. Análise dos desafios da didatização da escrita e da gramática no estágio supervisionado em língua materna. In: SILVA, W. (Org.). Letramento do professor em formação inicial: interdisciplinaridade no estágio supervisionado da licenciatura. Campinas: Pontes Editores. 2012. p. 53-81. 
DELU, Zhang et al.. The Development of Systemic Functional Linguistics in China. In: HASAN, R.; MATTHIESSEN, C.; WEBSTER, J. (Org.). Continuing Discourse on Language: a Functional Perspective. Volume 1. London: Equinox, 2005. p. 15-36.

EGGINS, Suzanne. An Introduction to Systemic Functional Linguistics. London: Continuum, 2004.

; MARTIN, J. R. Genres and Registers of Discourse. In: Teun A. van Dijk. (Ed.). Discourse as Structure and Process. London: SAGE, 1997. p. 230256.

GHADESSY, Mohan. On the Nature of Written Business Communication. In: GHADESSY, M. (Ed.). Register Analysis: Theory and Practice. London: Pinter Publishers, 1993. p. 149-164.

GONÇALVES, Adair; FERRAZ, Mariolinda. Teoria acadêmica e prática profissional na Licenciatura em Letras. In: Wagner R. Silva (Org.). Letramento do professor em formação inicial: interdisciplinaridade no estágio supervisionado da licenciatura. Campinas: Pontes Editores, 2012. p. 109-136.

GOUVEIA, Carlos. Texto narrativo. In: MATEUS, M.; PEREIA, D.; FISCHER, G. (Org.). Diversidade linguística na escola portuguesa. Lisboa: Fundação Calouste Gulbenkian, 2008. p. 113-118.

GYSEL, Edelweiss V. Blogs Segundo a tipologia textual baseada em contexto: proposta para análise textual em estudos da tradução, 2013. 186 f. Dissertação (Mestrado em Estudos da Tradução). Universidade Federal de Santa Catarina, Florianópolis, 2013.

HALLIDAY, M. Fuzzy Grammatics: A Systemic Functional Approach to Fuzziness in Natural Language. In: WEBSTER, Jonathan (Ed.). Computational and Quantitative Studies. London: Continuum. 1995. p. 211 - 238. 
. An Introduction to Functional Grammar. 2. ed. London: Edward Arnold, 1994.

. Part A. In: HALLIDAY, M.; HASAN, R. Language, Context and Text. 2. ed. Oxford: Oxford University Press. 1989. p. 3-49.

. Language as Social Semiotic: the social interpretation of language and meaning. London: Baltimore: Edward Arnold \& University Park Press, 1978.

. Explorations in the Functions of Language. London: Edward Arnold, 1973.

; GREAVES, William. Intonation in the grammar of English. London: Equinox, 2008.

; MATTHIESSEN, C. M. I. M. Halliday's Introduction to Functional Grammar. 4 Ed. London: Routledge, 2013.

; ___. An Introduction to Functional Grammar. 3 Ed. London: Hodder Education, 2004.

HASAN, Ruqaiya. The nursery tale as a genre. In: CHORAN, C.; BUTT, D.; WILLIAMS, G. (Ed.). Ways of Saying of Meaning: selected papers of Ruqaiya Hasan. London: Cassell. 1996. p. 61-72.

. The Structure of a Text. In: Michael A. Halliday and Ruqaiya Hasan. Language, Context and Text. 2. ed. Oxford: Oxford University Press, 1989. p. 52-69.

; MATTHIESSEN, C.; WEBSTER, J. J. Continuing Discourse on Language: a Functional Perspective. Volumes 1 and 2. London: Oakville: Equinox, 2007.

KOCH, Ingedore. Introdução à Linguística Textual: trajetória e grandes temas. São Paulo: Martins Fontes, 2004. 
MARCUSCHI, L. A. Produção textual, análise de gêneros e compreensão. São Paulo: Parábola Editorial, 2008.

MARTIN, James. Genre and Literacy: Modeling Context in Educational Linguistics. In: ZHENHUA, W. (Ed.). Language in Education: Collected Works of J.R. Martin, Volume 7. Shanghai: Shanghai Jiao Tong University Press, 2012. p. 133-159.

A context for genre: modelling social processes in functional linguistics. DEVILLIERS, J; STAINTON, R. (Ed.). Communication in Linguistics: Papers in Honour of Michael Gregory. Toronto: GREF (Theoria Series 10), 2001. 287-328.

. Analysing genre: functional parameters. In: CHRISTIE, F; MARTIN, J. (Ed.). Genre and Institutions. London: New York: Continuum, 1997. p. 3-39

. English text - systems and structure. Philadelphia: Amsterdam: John Benjamins Publishing Company, 1992.

; MATTHIESSEN, C. Modelling and Mentoring: Teaching and Learning from Home through School In: Leslie Barratt and Ahmar Mahboob (Org.). English in a Multilingual Context. Berlin: Springer Verlag, 2012. (In print)

; ROSE, D. Genre Relations: Mapping Culture. London: Oakville: Equinox, 2008.

; W__ Working with Discourse: Meaning Beyond the Clause. 2 ed. New York: Continuum, 2007.

; WHITE, P. R. R. The Language of Evaluation: Appraisal in English. New York: Palgrave Macmillan, 2005. 
MATTHIESSEN, Christian. English Lexicogrammar through Text: Text Typology and Lexicogrammatical Patterns. Hong Kong: The Hong Kong Polytechnic University - PolyU, 2013. (artigo inédito)

. Appliable Discourse Analysis. Hong Kong: The Hong Kong Polytechnic University - PolyU, 2012. (artigo inédito)

. Ideas and News Directions. In: HALLIDAY, M; WEBSTER, J. (Ed.). Continuum Companion to Systemic Functional Linguistics. London: Continuum, 2009. p. 12-58.

. English Grammar through Text: Text Typology and Grammatical Patterns. Department of Linguistics, Macquarie University; Centre for Language in Social Life, Macquarie University; Systemic Meaning Modelling Group; Halliday Centre for Intelligent Applications of Language Studies. Hong Kong City University, 2007. (inédito)

. Register in the Round: Diversity in a Unified Theory of Register Analysis. In: GHADESSY, M. (Ed.). Register Analysis: Theory and practice. London: Pinter Publishers. 1993. p. 221-292.

; HALLIDAY, Michael. Systemic Functional Grammar: A First Step into the Theory. China: Higher Education Press, 2009.

; TERUYA, Kazuhiro; LAM, Marvin. Key Terms in Systemic Functional Linguistics. London: Continuum, 2010.

;____ WU, Canzhong. Multilingual studies as a multi-dimentional space of interconnected language studies. In: WEBSTER J. (Ed.). Meaning in context: implementing intelligent applications of language studies. London: New York: Continuum, 2008. p. 146-220.

MELO, Lívia; ANDRADE, Karylleila; SILVA, Wagner. Trabalho escolar com vocabulário em relatórios de estágios supervisionados em ensino de língua 
Inglesa. Trabalhos em Linguística Aplicada. Campinas: IEL/Unicamp, v. 51, n. 1, p. 51-75, 2012.

MOTTA-ROTH, Désirée. Sistemas de gêneros e recontextualização da ciência na mídia eletrônica. In: Gragoatá, Niterói (EdUFF), v. 28, n. 1, p. 153174, 2010.

; HEBERLE, Viviane. O conceito de estrutura potencial do gênero de Ruqayia Hasan. In: MEURER, J.; BONINI, A.; MOTTA-ROTH, D. (Org.). Gêneros: teorias, métodos, debates. São Paulo: Parábola Editorial, 2005. p. 12-28.

NININ, Maria; BARBARA, Leila. Engajamento na perspectiva linguística sistêmico-funcional em trabalhos de conclusão de curso de Letras. In: Trabalhos em Linguística Aplicada, Campinas (Unicamp/IEL), v.52, n.1, p. 127-146, 2013.

RIBEIRO, Ana; ROCHA, Jorge; COSCARELLI, Carla. Linguagem, tecnologia, gêneros textuais e ensino: dez anos de diálogo com Luiz Antônio Marcuschi. In: Revista da Anpoll: Anpoll 25 anos - Linguística: percursos e perspectivas. Anpoll, n. 29, v. 1, p. 169-189, 2010.

SILVA, Wagner. Escrita do gênero relatório de estágio supervisionado na formação inicial do professor brasileiro. In: Revista Brasileira de Linguística Aplicada, Belo Horizonte (UFMG/ALAB), v. 13, n. 1. p. 171-195, 2013.

. Gêneros textuais em aulas de Língua Portuguesa no Ensino Médio brasileiro. In: Linguagem \& Ensino. Pelotas: UCPel, v. 15, n. 2, p. 387-418, 2012a.

. Letramento do professor em formação inicial: interdisciplinaridade no estágio supervisionado da licenciatura. Campinas: Pontes Editores, 2012 b. 
. Proposta de análise textual-discursiva do gênero relatório de estágio supervisionado. DELTA - Documentação de Estudos em Linguística Teórica e Aplicada. São Paulo: PUC/SP, v. 28, n. 2, p. 281-305, 2012c.

. Estudo da gramática no texto: demandas para o ensino e a formação do professor de língua materna. Maringá: Eduem, 2011.

. Seleção textual no ensino interdisciplinar por projetos. In: Revista Brasileira de Linguística Aplicada, Belo Horizonte, (UFMG/ALAB), v. 9, n. 1, p. 17-39, 2009a.

. Algumas contribuições da linguística aplicada para o ensino de escrita em aulas de língua materna no Brasil. In: Revista Investigações (UFPE), Recife, v. 22, n. 2, p. 135-160, 2009 b.

; FAJARDO-TURBIN, Ana. Como fazer relatórios de estágio supervisionado: formação de professores nas licenciaturas. Brasília: Liber Livro Editora, 2012.

_____. Relatório de estágio supervisionado como registro da reflexão pela escrita na profissionalização do professor. In: Revista Polifonia (UFMT), Cuiabá, v. 18, p. 97-123, 2011.

; MENDES, Aliny. Reescrita na formação inicial de professores: um estudo da produção do gênero relatório de estágio supervisionado. In: $\mathrm{Ca}$ derno de Letras, Pelotas, (UFPEL), v. 14, n. 2, p. 134-155, 2012.

; PEREIRA, Bruno. Letramento acadêmico no estágio supervisionado da licenciatura. Raído. Dourados: Editora da UFGD, v. 7, n. 13, p. 37$59,2013$.

TENUTA, Adriana; OLIVEIRA, Ana. Livros didáticos e ensino de línguas estrangeiras: a produção escrita no PNLD-2011/LEM. In: Linguagem \& Ensino (UCPel), Pelotas, v. 15, n. 2, p. 315-336, 2011. 
THOMPSON, Geoff; COLLINS, Heloisa. Interview with M. A. K. Halliday, Cardiff, July 1998. DELTA - Documentação de Estudos em Linguística Teórica e Aplicada. São Paulo: PUC/SP, 2001, v.17, n.1, p. 131-153.

VIAN JR. Orlando. Conceito de gênero e análise de textos de vídeos institucionais. 1997. Dissertação (Mestrado em Linguística Aplicada e Estudos da Linguagem) - Pontifícia Universidade Católica de São Paulo, São Paulo. 1997.

; IKEDA, Sumiko. O ensino do gênero resenha pela abordagem sistêmico-funcional na formação de professores. In: Linguagem \& Ensino (UCPel), Pelotas, v. 12, n. 1, p. 13-32, 2009.

; LIMA-LOPES, Rodrigo. A perspectiva teleológica de Martin para a análise dos gêneros textuais. In: MEURER, J.; BONINI, A.; MOTTA-ROTH, D. (Org.). Gêneros: teorias, métodos, debates. São Paulo: Parábola Editorial, 2005. p. 29-45.

; SOUZA, Anderson; ALMEIDA, Fabiola. (org.). A linguagem da avaliação em língua portuguesa: estudos sistêmico-funcionais com base no sistema de avaliatividade. São Carlos: Pedro \& João Editores, 2011. 
